\title{
1 A new paradigm for leprosy diagnosis based on host gene expression
}

\section{Insights from leprosy lesions transcriptomics}

3 Thyago Leal-Calvo', Charlotte Avanzi ${ }^{2, \# a}$, Mayara Abud Mendes ${ }^{1}$, Andrej Benjak ${ }^{2, \# b, ~}$

4 Philippe Busso², Roberta Olmo Pinheiro1, Euzenir Nunes Sarno , Stewart T. Cole ${ }^{2,3}$,

5 Milton O. Moraes ${ }^{1^{*}}$

\section{Affiliations}

$7 \quad{ }^{1}$ Laboratório de Hanseníase, Instituto Oswaldo Cruz, FIOCRUZ, Rio de Janeiro, Rio

8 de Janeiro, Brazil

92 Global Health Institute, École Polytechnique Fédérale de Lausanne, Lausanne,

10 Switzerland

$11{ }^{3}$ Institut Pasteur, Paris, France

12 \#aCurrent address: Department of Microbiology, Immunology and Pathology,

13 Mycobacteria Research Laboratories, Colorado State University, Fort Collins,

14 Colorado, United States of America

$15{ }^{\# b}$ Current address: Department for BioMedical Research, Oncogenomics Laboratory,

16 University of Bern, Bern, Switzerland

17 * Corresponding author

18 E-mail: milton.moraes@fiocruz.br (MOM) 


\section{Abstract}

23 Transcriptional profiling is a powerful tool to investigate and detect human diseases.

24 In this study, we used bulk RNA-sequencing (RNA-Seq) to compare the

25 transcriptomes in skin lesions of leprosy patients or controls affected by other dermal 26 conditions such as granuloma annulare, a confounder for paucibacillary leprosy. We 27 identified five genes capable of accurately distinguishing multibacillary and paucibacillary leprosy from other skin conditions. Indoleamine 2,3-dioxygenase 1 (IDO1) expression alone was highly discriminatory, followed by $T L R 10, B L K, C D 38$, and SLAMF7, whereas the HS3ST2 and CD4OLG mRNA separated multi- and paucibacillary leprosy. Finally, from the main differentially expressed genes (DEG) and enriched pathways, we conclude that paucibacillary disease is characterized by epithelioid transformation and granuloma formation, with an exacerbated cellular immune response, while multibacillary leprosy features epithelial-mesenchymal transition with phagocytic and lipid biogenesis patterns in the skin. These findings will help catalyze the development of better diagnostic tools and potential host-based therapeutic interventions. Finally, our data may help elucidate host-pathogen interplay driving disease clinical manifestations.

\section{Author Summary}

Despite effective treatment, leprosy is still a significant public health issue in more than 120 countries, with more than 200000 new cases yearly. The disease is caused mainly by Mycobacterium leprae, a slow-growing bacillus still uncultivable in axenic media. This limitation has hampered basic research into host-pathogen 
44 interaction and the development of new diagnostic assays. Currently, leprosy is

45 diagnosed clinically, with no standalone diagnostic assay accurate enough for all

46 clinical forms. Here, we use RNA-seq transcriptome profiling in leprosy lesions and

47 granuloma annulare to identify mRNA biomarkers with potential diagnostic

48 applications. Also, we explored new pathways that can be useful in further

49 understanding the host-pathogen interaction and how the bacteria bypass host

50 immune defenses. We found that IDO1, a gene involved with tryptophan catabolism,

51 is an excellent candidate for distinguishing leprosy lesions from other dermatoses.

52 Additionally, we observed that a previous signature of keratinocyte development and

53 cornification negatively correlates with epithelial-mesenchymal transition genes in the

54 skin, suggesting new ways in which the pathogen may subvert its host to survive and

55 spread throughout the body. Our study identifies new mRNA biomarkers that can

56 improve leprosy diagnostics and describe new insights about host-pathogen

57 interactions in human skin. 


\section{Introduction}

Leprosy is a chronic infectious disease caused mainly by the slow-growing

60 intracellular pathogen Mycobacterium leprae that does not grow in axenic media. This

bacterium resides preferentially in skin macrophages and Schwann cells in peripheral

nerves, inducing dermatosis and/or neuritis. Patients can present several distinct

clinical forms according to their immune response, histopathological characterization,

and bacterial load. A localized tuberculoid form (TT) is characterized by low bacterial counts and a strong cellular immune response. Conversely, in the opposite lepromatous (LL) pole, a disseminated form, patients exhibit several lesions, a predominantly humoral response, and a high bacterial load in the tissues [1-3].

Borderline forms are classified according to their proximity to the poles. For operational and treatment purposes, leprosy is classified by the World Health Organization as paucibacillary $(\mathrm{PB})$ or multibacillary $(\mathrm{MB})$, based on the number of skin lesions, associated with nerve involvement or the bacilli detection in slit-skin smears [4].

Early and precise diagnosis is instrumental to leprosy control since delay in diagnosis leads to late multidrug therapy, higher disability risk, and continuing transmission, as highlighted by the 200,000 new cases consistently reported annually in the last 10 years [4,5]. However, bacteriological, immunological, genetics or molecular methods are not sufficient for specific diagnosis when used alone.

77 Diagnosis most commonly relies on clinical evaluation, occasionally complemented with histopathological examination and bacterial counts, but these procedures are mostly performed in national reference centers $[4,6]$. 

technologies, such as molecular identification of $M$. leprae, serological tests for specific bacterial antigens, and quantification of host biomarkers in plasma or in vitro whole blood assays (WBA) [7-9]. Overall, all methods outperform standard clinical

84 diagnosis and can compensate for the low accuracy in detecting PB patients $[4,7,8,10-14]$. Yet, until now such investigations involved comparing confirmed leprosy cases against healthy endemic controls, who are not representative of individuals with suspected leprosy. Here, other skin conditions represent a better comparator.

Identification of markers for early infection is hindered by our poor understanding of pathogenicity and the mechanism by which patients develop one or the other form of leprosy, and nerve injuries [15]. Gene expression signatures have

91 been used as diagnostic tools for several illnesses, from infectious [10-12,14] and autoimmune diseases $[16,17]$ to cancer $[18-20]$. Some signatures have already been approved for clinical use [12,21-23]. In leprosy, findings from past studies indicate the great potential of expression profiling for disease diagnosis [24-27]. Nonetheless, they were limited by the number of patients [28], or lacked proper epidemiological controls, such as differential diagnosis groups.

Here, we applied a combination of bulk RNA sequencing and quantitative validation by RT-qPCR on RNA extracted from skin biopsies of various leprosy forms and from non-leprosy patients to define a specific leprosy host signature applicable to 100 diagnosis. Then, we explored gene expression patterns to improve our understanding of the immunopathogenic mechanisms towards leprosy polarization. 


\section{Results}

\section{Discrimination of leprosy vs. non-leprosy lesions based on}

\section{4 mRNA expression}

RNA sequencing was used for pinpointing host candidate genes capable of differentiating leprosy lesions from one of the commonest differential diagnoses of leprosy, granuloma annulare (GA), and from healthy skin. RNA from skin lesions of all leprosy clinical forms $(n=33)$, plus $G A(n=4)$ and healthy skin $(n=5)$ were sequenced (S1 Table). Differentially expressed genes (DEG) in leprosy vs. non-leprosy (GA + healthy skin) samples resulted in $1160 \mathrm{DEG}$ with a $\left|\log _{2} \mathrm{FC}\right| \geq 1$ and FDR $\leq 0.01$, with

111961 upregulated in leprosy forms compared to non-leprosy (Fig 1A-B and S2 Table).

112 Exploratory hierarchical clustering of the DEG with $\left|\log _{2} \mathrm{FC}\right| \geq 1$ and FDR $<0.01$ grouped all patients' samples into roughly two clusters, except for two: one BL leprosy

114 and one GA that clustered apart from samples with the same diagnosis (Fig 1C). Gene

115 Ontology enrichment analysis of up-regulated genes in leprosy compared to non116 leprosy showed enrichment for biological processes associated with leukocyte 117 activation, $\mathrm{T}$-cell activation, immune response, response to the bacterium, neutrophil degranulation, cell killing, cytokine secretion, purinergic receptor signaling pathway, and regulation of defense response to viruses by the host (Fig 1D and S3 Table). 
bioRxiv preprint doi: https://doi org/101101/2021.07 30.454441; this version posted September 22, 2021. The copyright holder for this preprint (which was not certified by peer review) is the author/funder, who has granted bioRxiv a license to display the preprint in perpetuity. It is made available under aCC-BY-NC-ND 4.0 International license.

A

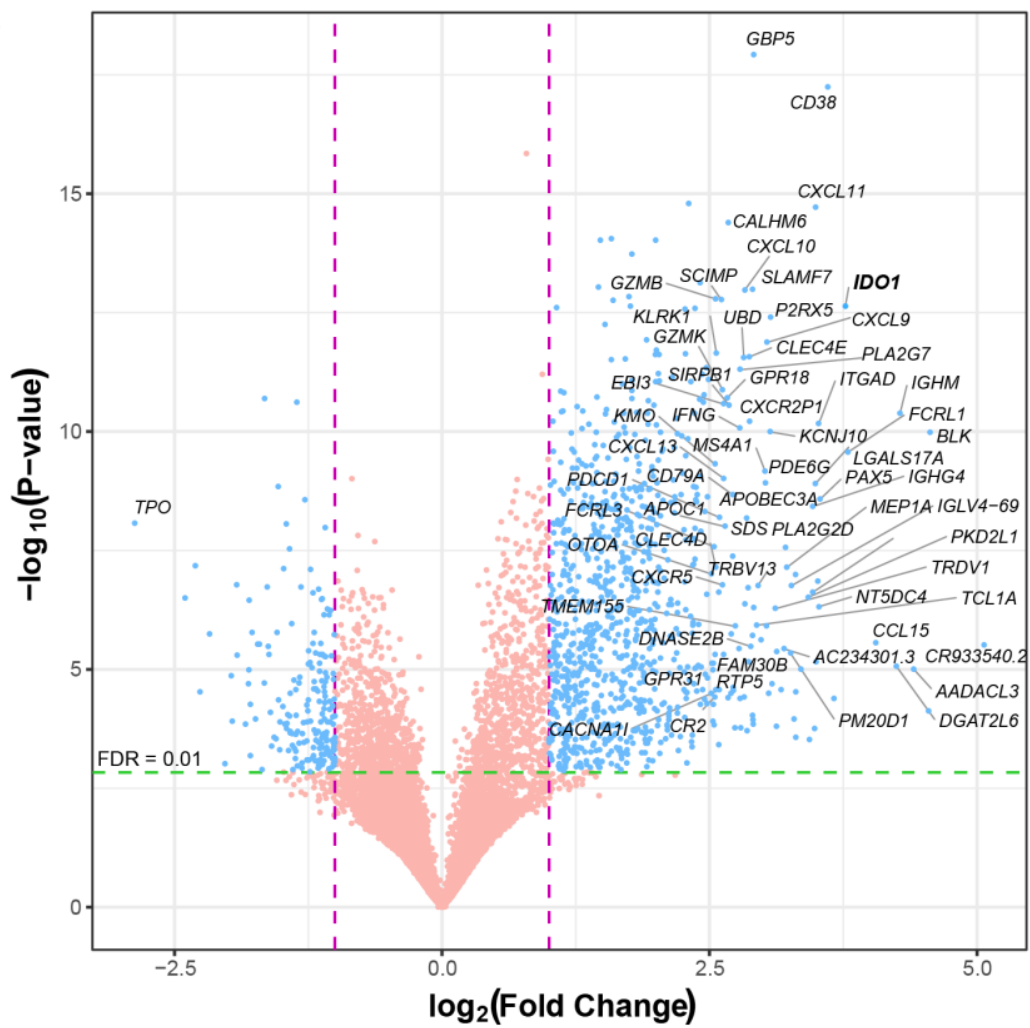

B
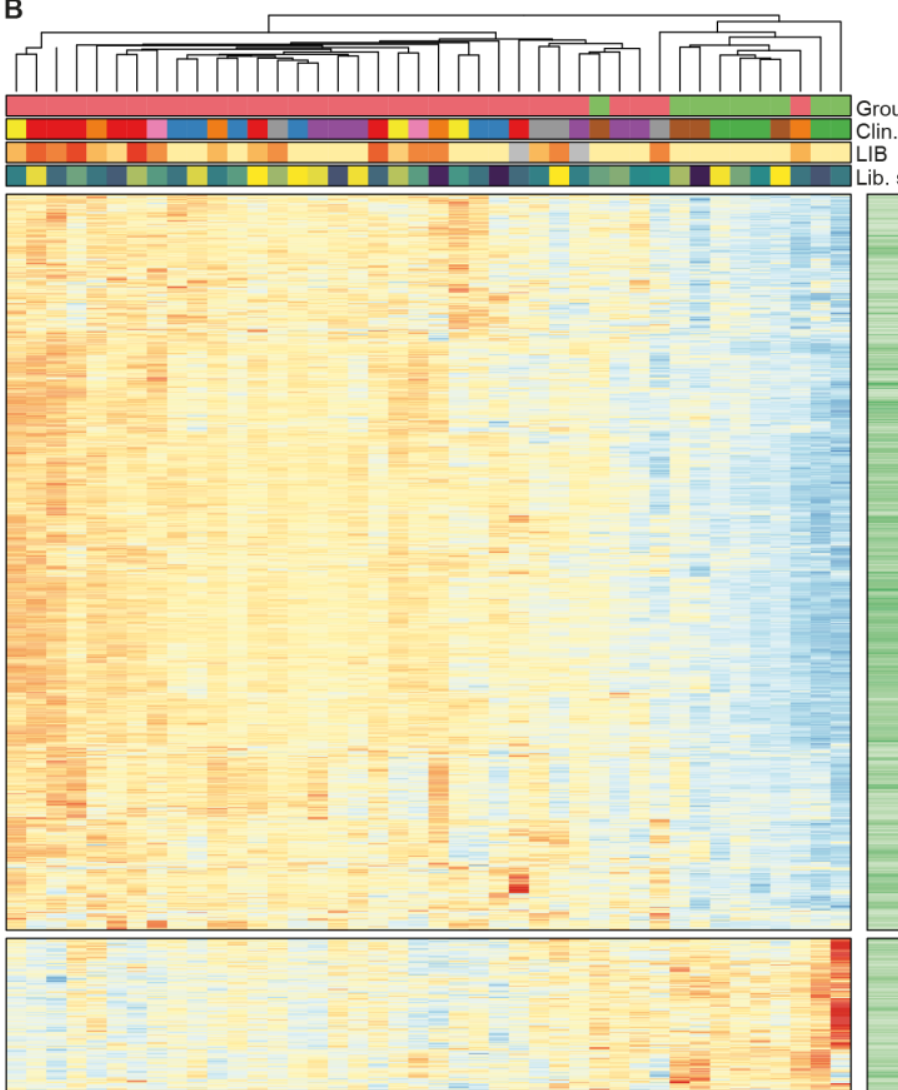

Clin. form

Lib. size
-35
30
-25
-20
-20
-15
-10

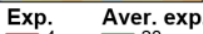

Lep
NL

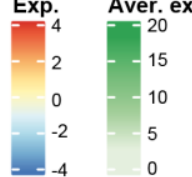

C

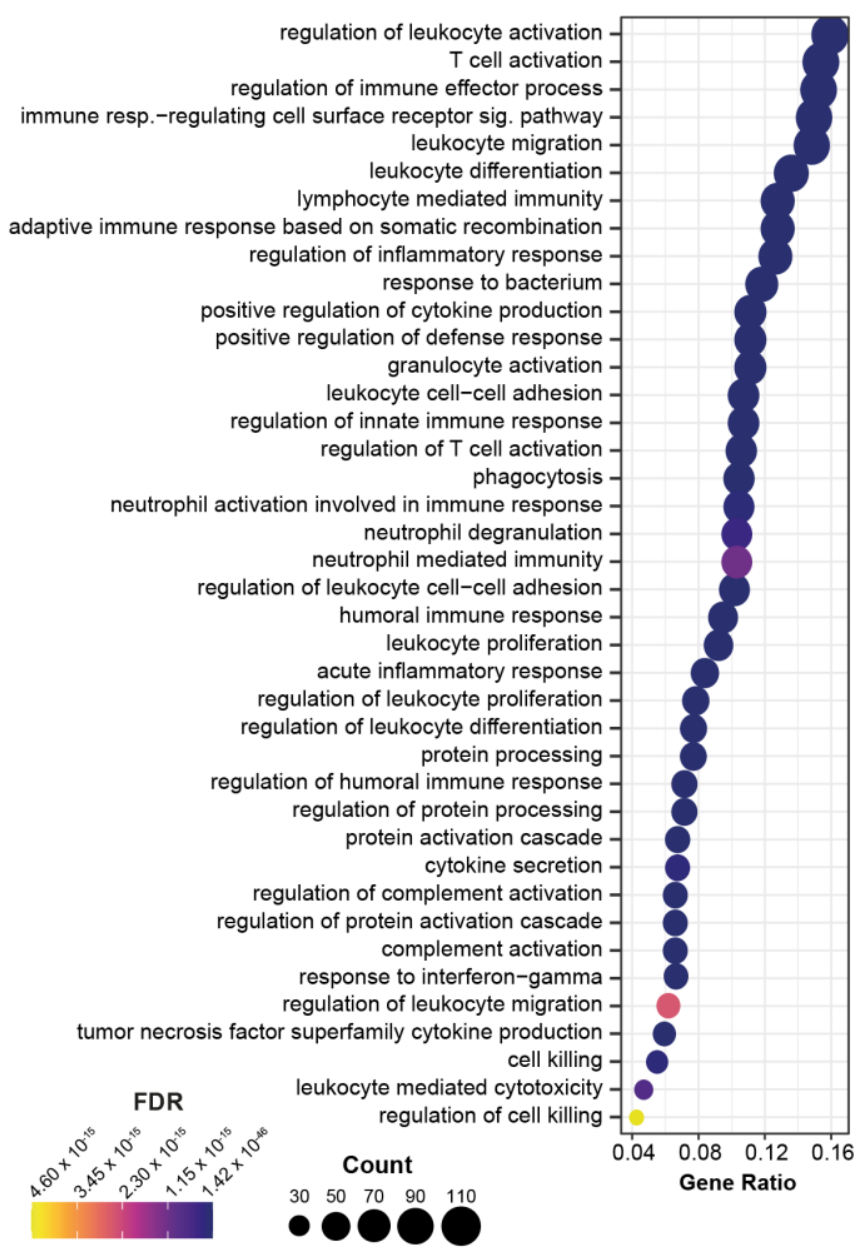


124 leprosy vs. non-leprosy. (A) Volcano plot depicting DEG from leprosy vs. non125 leprosy, where violet dashed line marks $\left|\log _{2} \mathrm{FC}\right|=1$. For clarity, gene symbols are shown only for the largest $\log _{2}$ FC. (B) Heatmap with hierarchical clustering of samples based on expression of the DEG from leprosy vs. non-leprosy comparison. Color scale 128 ranges from lower expression (blue) to higher expression (red). Library size is given 129 in millions. LIB, logarithmic index of bacilli. (C) Biological processes from GO enriched 130 for up-regulated DEG from leprosy vs. non-leprosy comparison. FDR, false discovery rate; NL, non-leprosy; GA, granuloma annulare; non-leprosy: GA + healthy individuals.

A total of 15 genes with the largest effect size $\left(\left|\log _{2} F C\right| \geq 1.5, F D R<0.001\right)$,

134 highest area under the curve (AUC), and plausible involvement with leprosy pathogenesis (S4 Table) were then validated using a two-step RT-qPCR with a new, larger, and more heterogeneous dataset including skin lesion samples from leprosy

137 patients $(n=25)$, and other common dermatoses $(n=23)$ (S1 Table). Other dermatological diseases (ODD) included dermatitis $(n=7)$, eczema $(n=1)$, erythema $(n=4)$, GA $(n=6)$, lichen planus $(n=2)$, psoriasis $(n=2)$ and pityriasis alba $(n=1)$

140 Table). A total of 12 samples per group was estimated to be sufficient to attain a power 141 of $85 \%$ based on the Welch t-test (PB vs. ODD, MB vs. ODD) with alpha set at 0.03 142 to replicate the standardized effect size $\left(\log _{2} F C / S D\right)$ estimated from RNA sequencing.

143 Relative expression using the new sample set by RT-qPCR is shown in Fig 2A. Indeed,

144 the validation data are in agreement with RNA sequencing, because 11 tested genes 145 were replicated by RT-qPCR in terms of difference between mean expression (effect 146 size in $\log _{2} \mathrm{FC}$ ), except for STAP1, GBP3, APOL3 and CCR7 in PB vs. ODD 147 comparison and CCR7 in MB vs. ODD (Fig 2B-C, S5 Table). As for differentiating 
bioRxiv preprint doi: https//doi.org/10.1101/2021.07.30.454441· this version posted September 22, 2021. The copyright holder for this preprint (which was not certified by peer review) is the author/funder, who has granted bioRxiv a license to display the preprint in perpetuity. It is made available under aCC-BY-NC-ND 4.0 International license.

148 leprosy per se vs. ODD, genes IDO1, BLK (exon 11), CD38, CXCL11, and SLAMF7,

149 all had an area under the curve (AUC) of at least $96 \%$ with their lower bound $97 \%$ confidence intervals above 90\% (Fig 2A, Fig 3C, S6 Table).

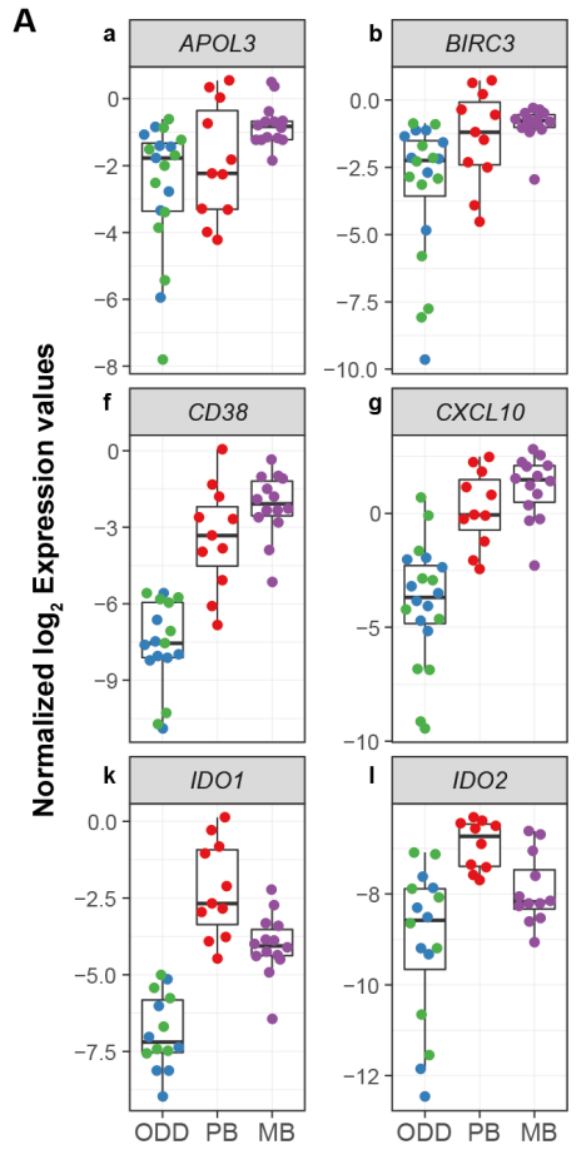

B

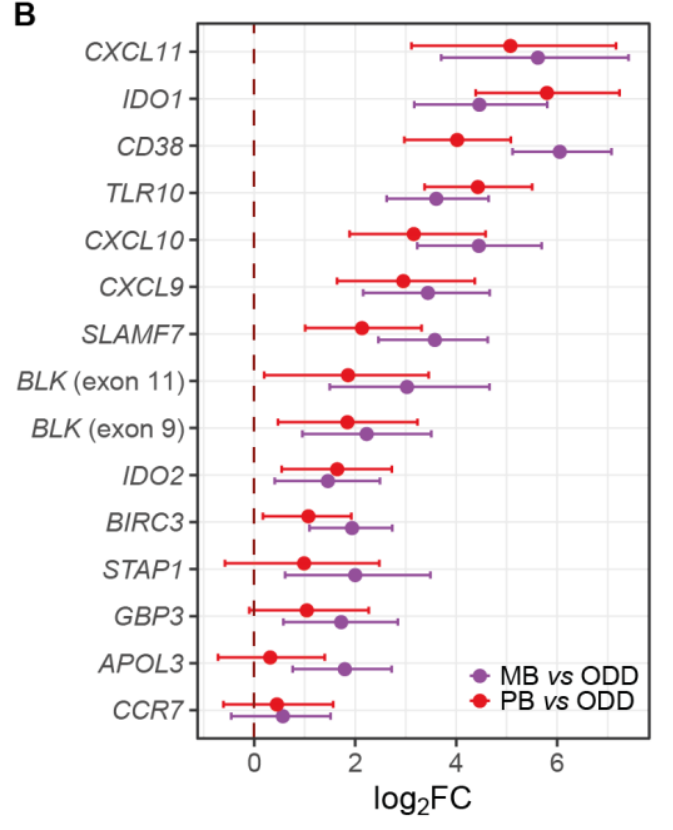

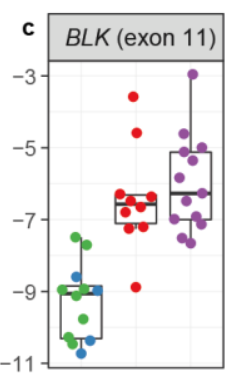
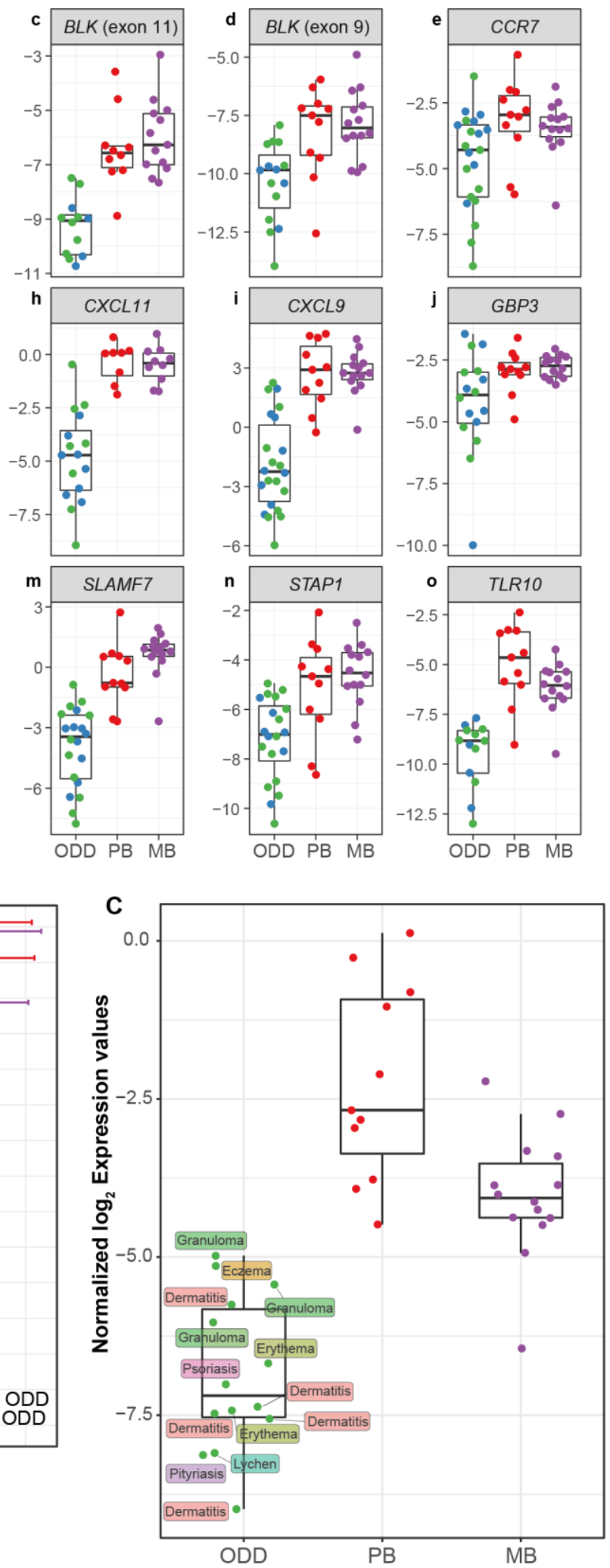
Fig 2. Technical and biological validation for selected DEG discovered from RNA

or negative (green). (B) $\log _{2} \mathrm{FC}$ from MB-ODD and PB-ODD comparisons estimated

156 from Bayesian linear mixed models and their 95\% credible intervals. (C) Tukey boxplot highlighting IDO1 RT-qPCR normalized $\log _{2}$ expression values by final diagnosis grouped into ODD category. Missing values are omitted. samples simultaneously. The analysis roughly revealed three major clusters (Fig 3A).

At the highest tree subdivision, one small cluster $(n=6)$ with the dendrogram grouped in light brown was composed of ODD samples with lower expression levels (Fig 3A). Due to several ODD having missing values, we confirmed that these samples had similar gene expression for the reference genes, thereby eliminating the possibility of insufficient cDNA input. Another cluster, grouped in the light purple dendrogram, included all MB and most PB samples (except four in light yellow dendrogram). GA samples displayed two patterns, the first with two samples showing undetectable IDO1 expression (Fig 3A, bottom star symbols). The second set $(n=4)$ is scattered among other ODD samples (Fig 3A). It can be seen that GA and PB samples show highly 172 similar expression profiles for some genes (Fig 3A bottom diamond symbols), 173 reinforcing the difficulty in clinically discriminating between these two conditions, and 174 underlining the relevance of their inclusion in our comparisons [29-31]. 

obtained with the expanded sample panel tested by RT-qPCR, we uncovered two

177 major patterns separating leprosy lesions from ODD (Fig 3B). As expected, MB 178 samples appeared more homogeneous than PB and ODD samples, while the latter 179 were more dispersed revealing heterogeneous expression patterns (Fig 3B).

Next, we quantified the individual classification potential of these genes in 181 distinguishing leprosy from ODD using ROC analysis on RT-qPCR data. IDO1 182 expression alone was found to be $98 \%$ accurate using an arbitrary threshold, followed 183 by $B L K$ (exon 11), CD38, CXCL11, and SLAMF7 (Fig 3C and S6 Table). Finally, to 184 confirm the causal link between mycobacteria and our gene-set, we evaluated the 185 mRNA profiles induced by other live-mycobacteria using a public RNA-seq dataset 186 [32]. We observed that most gene expression signatures, including IDO1, could be 187 successfully replicated as induced by either M. leprae and/or other mycobacteria (Fig 1881 in Appendix S1 and S7 Table). By contrast, some of the tested genes such as BLK, 189 CXCL9, MS4A1, and TLR10 were not differentially expressed in any of the in vitro 190 assays with mycobacteria (Fig 1 in Appendix S1 and S7 Table). 
A

B
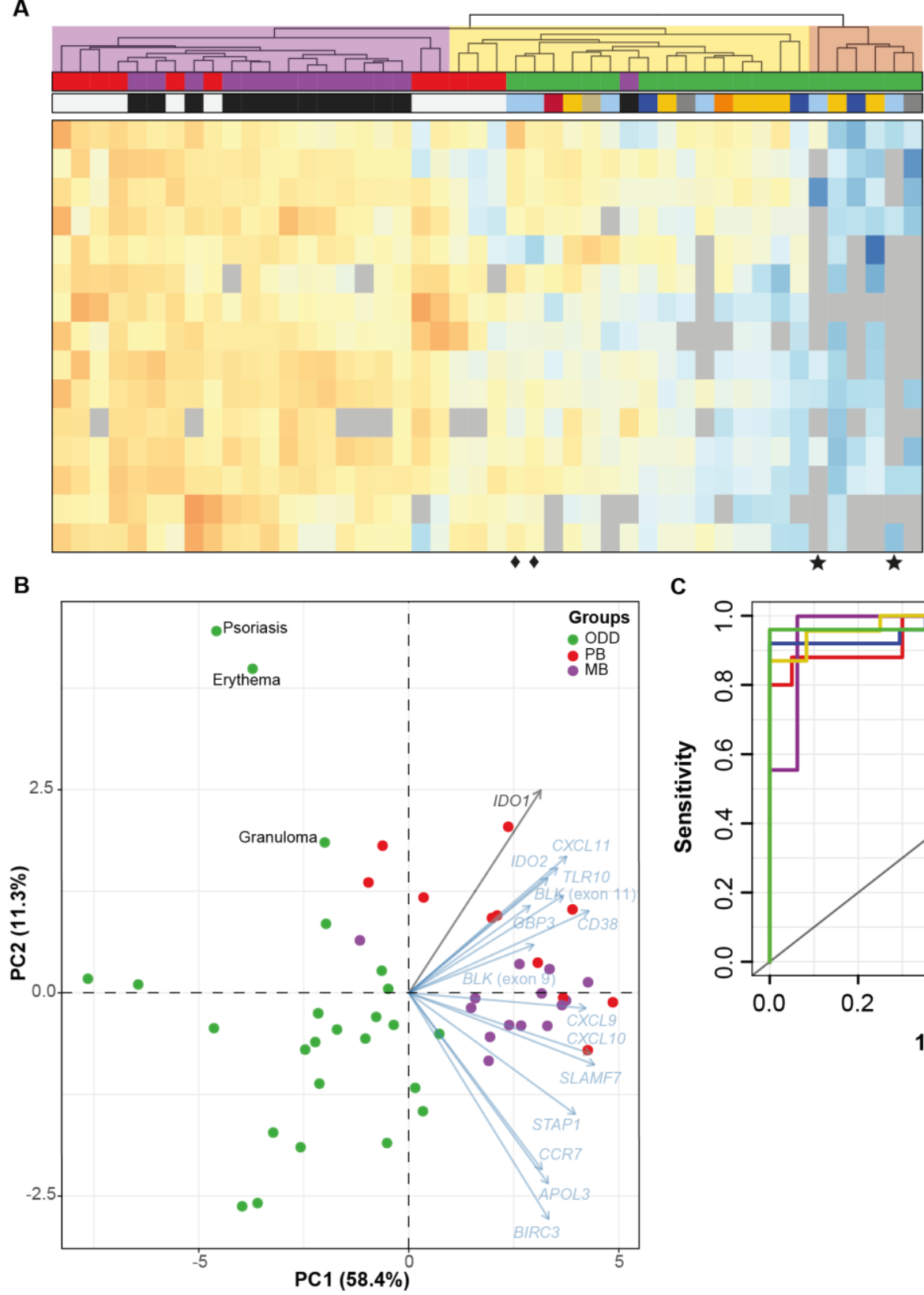

C

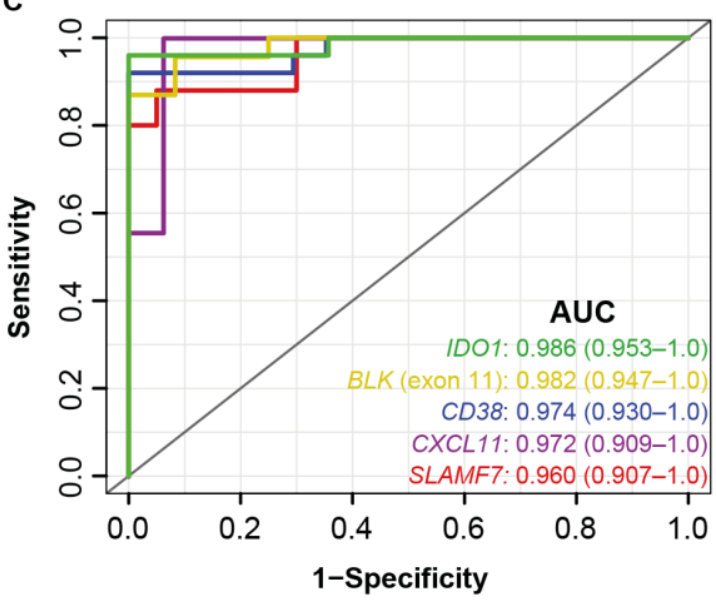

193 Fig 3. Hierarchical clustering of $R T-q P C R$ replicated DEG and ROC analysis. (A)

194 Hierarchical clustering with scaled and centered normalized $\log _{2}$ RT-qPCR expression

195 values (arbitrary units) and annotated according to group and specific diagnosis.

196 Dendrogram tree was cut arbitrarily and cluster analysis is for hypothesis generating

197 purposes only. Two samples had more than 13 missing expression values and were

198 removed from A. (B) Principal component analysis (PCA) with 15 genes measured by

199 RT-qPCR and using log2 normalized scaled data. For PCA only, missing values were 
200 imputed by the gene arithmetic mean. NA, not amplified, i.e., $\mathrm{Cp}>40$. In this regard, 201 there were two outliers (psoriasis and erythema), which are samples with high 202 numbers of NA values and that were imputed using the gene arithmetic mean. (C) 203 Receiver operating characteristic analysis for genes with largest AUC (97\% 204 confidence intervals) from RT-qPCR replication samples (complete data are shown in 205 S6 Table). See also S1 Appendix and S1 Fig.

\section{MB and PB gene expression profiling and mRNA-based}

\section{7 classifier}

To define a small subset of genes with high classificatory potential (i.e. with non-overlapping expression values) to distinguish MB from PB lesions, we performed a penalized logistic regression (LASSO) model with $\mathrm{k}$-fold cross-validation trained on

211 the public microarray dataset [24]. This dataset was chosen because of the higher 212 number of PB/MB samples compared to our RNA-seq dataset. As a result, three genes 213 with non-zero coefficients were selected by the cross-validated LASSO model: 214 HS3ST2, CD4OLG, and CCR6, but only the first two genes were most frequently $215(\sim 80 \%)$ selected across 10,000 bootstrapped samples within the training dataset (Fig 2164 A-B). The median misclassification error estimated by the resampling was about $4 \%$ $217( \pm 5.4 \%$ median absolute deviation), ranging from $0 \%$ to $32 \%$ (Fig $4 \mathrm{C}$ ). Instability 218 assessment in the number of selected genes by LASSO (Fig 4D) showed that most 219 iterations resulted in four non-zero genes (range, 1-20). The final model containing the 220 three genes (HS3ST2, CD4OLG, and CCR6) was evaluated on two test RNA-seq 221 datasets: our dataset and the one from Montoya et al. including MB $(n=9)$ and PB $222(n=6)$ groups [28]. Penalized logistic regression demonstrated an accuracy of $100 \%$ 
223 (lower 95\% Cls: 86.8\% and 78.2\%, respectively) in classifying MB from PB samples

224 in both test RNA-seq datasets; yet, the Brier score indicated a better performance in

225 Montoya's et al. dataset, probably due to a more homogenous sampling (Fig 4E-F).

226 The HS3ST2 gene was consistently more expressed in MB leprosy lesions compared

227 to PB, whereas the opposite was observed for CD4OLG (Fig 4E-H) and CCR6 (S2

228 Fig). In both datasets, the combined expression levels of HS3ST2 and CD4OLG

229 showed good discrimination between the two groups (Fig 4E-H). However, given the

230 sample size and the bootstrapped estimates, it is not currently possible to exclude

231 CCR6 from the model without additional replication. 
bioRxiv preprint doi: https//doi.org/10.1101/2021.07.30.454441· this version posted September 22 2021. The copyright holder for this preprint (which was not certified by peer review) is the author/funder, who has granted bioRxiv a license to display the preprint in perpetuity. It is made available under aCC-BY-NC-ND 4.0 International license.

A

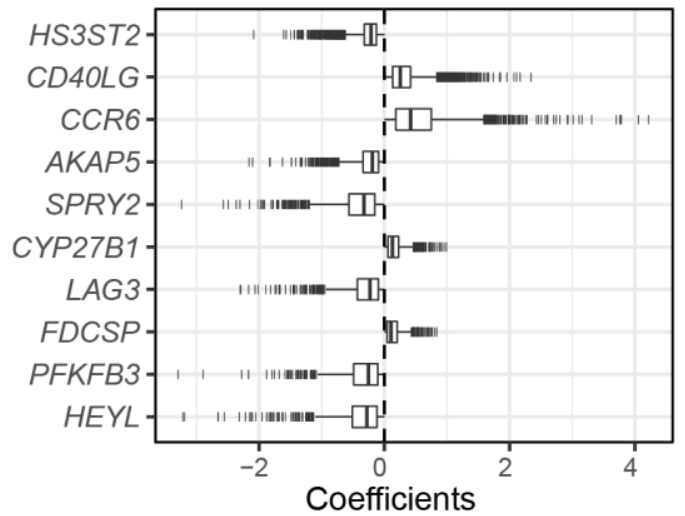

C

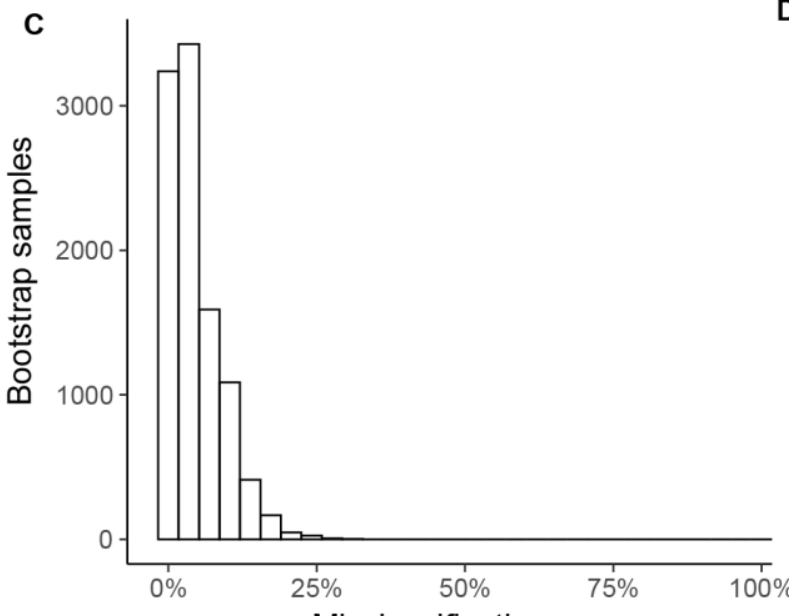$$
\text { E }
$$

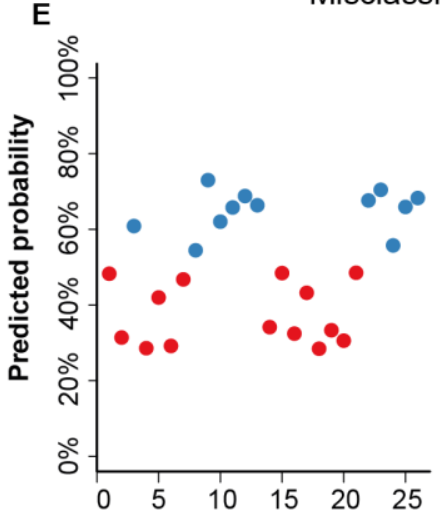

G

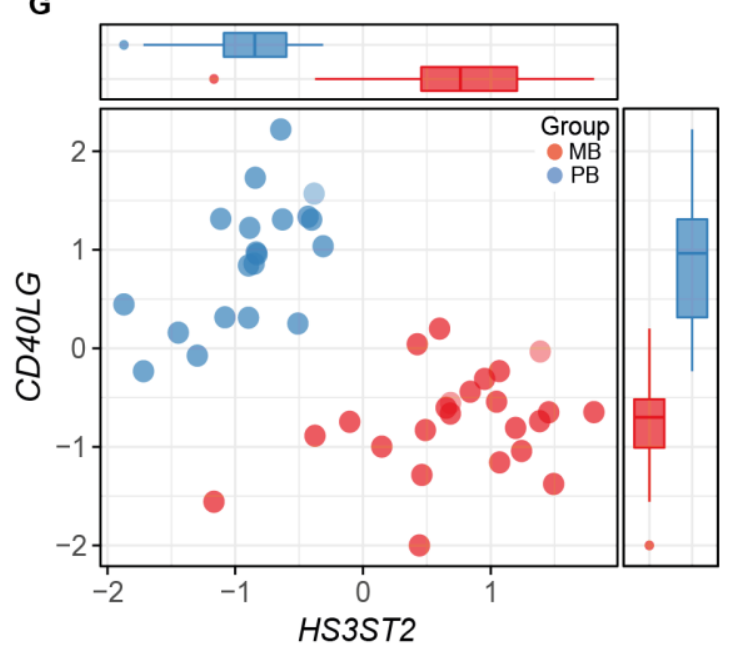

D
B
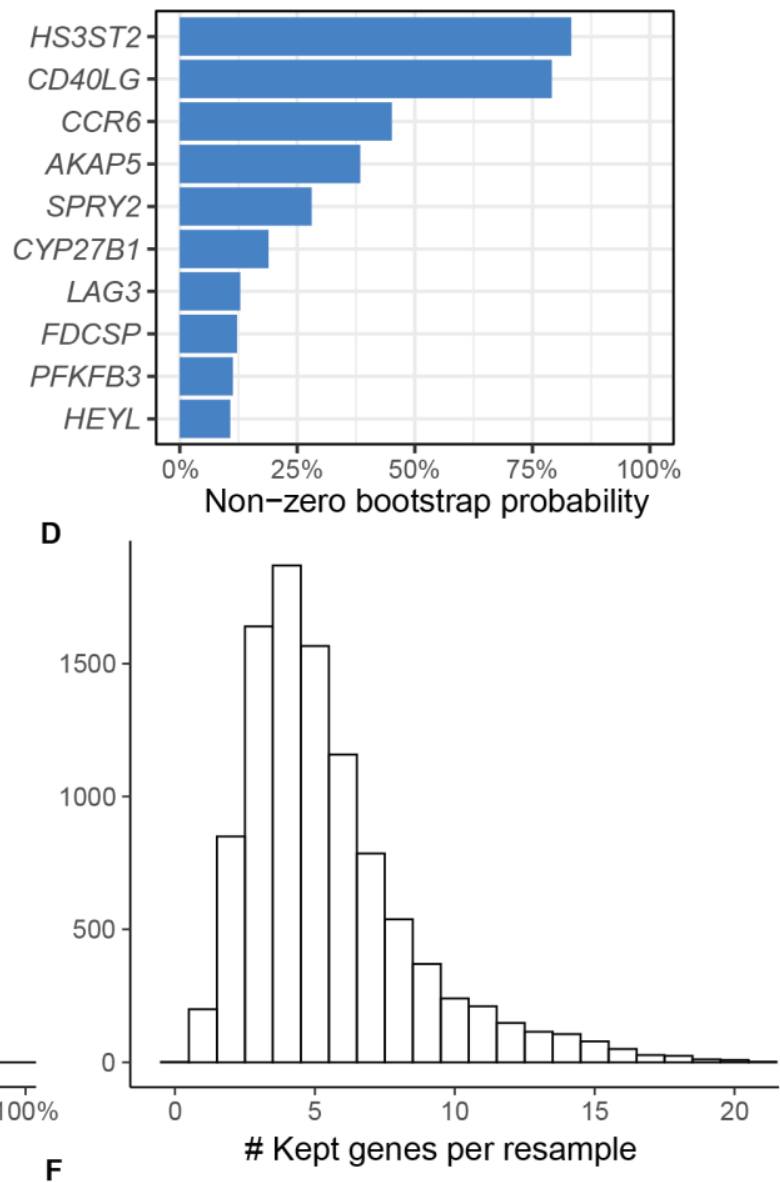

$\mathrm{F}$
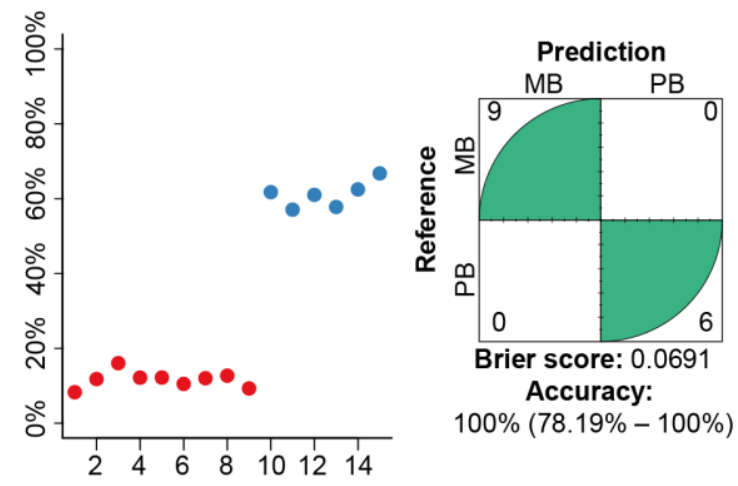

H

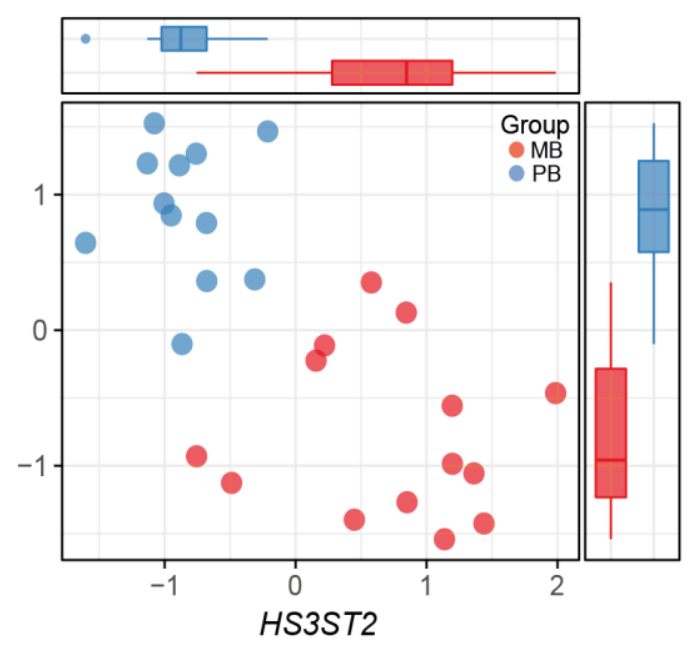


Fig 4. Gene candidates identified with the penalized logistic regression (LASSO)

Coefficients (log odds) from the top 10 most selected genes (i.e., non-zero) across 10,000 bootstrap samples using the microarray from Belone et al. as training dataset.

(B) Frequency of non-zero coefficients across all bootstrap samples.

238

239

240

241

242

243

244

245

246

Misclassification error distribution estimated from 4-fold cross-validation (k-) across 10,000 bootstrap samples, with median error of $3.70 \%( \pm 5.4 \%$ median absolute deviation). (D) Number of genes kept across all resamples. Predicted probability from the final model performance on this study test RNA-seq (E) and Montoya et al. RNAseq $(F)$. Normalized log2 gene expression (z-score) of the two most frequently selected variables for distinguishing MB from PB samples in the $(\mathrm{G})$ microarray training dataset and $(\mathrm{H})$ this study test RNA-seq. PB, paucibacillary leprosy; MB, multibacillary leprosy. Tukey box plots with 1st, 2 nd and 3rd quartiles $\pm 1.5 \times$ inter quartile range (IQR) whiskers. See also S2 Fig.

Next, to assess the dichotomy beyond cellular vs. humoral response in leprosy lesions [33,34], a comparison of gene expression in $M B$ leprosy $(L L+B L+B B)$ vs. $P B$ $(\mathrm{TT}+\mathrm{BT})$ skin lesions was performed. Differential expression analysis with $\left|\log _{2} \mathrm{FC}\right| \geq$ 1 and FDR $\leq 0.01$ resulted in 112 DEGs; 69 up-regulated and 43 down-regulated (Fig 5A and S8 Table). In addition, we compared DEG to the public microarray data available in Gene Expression Omnibus (GEO) from Belone et al. [24,35] using only the FDR cutoff. With an FDR $<0.01,161$ DEGs were common to both studies, all except one showed concordant modulation characterized by an overall high correlation coefficient and concordance index, irrespective of the technology used, the 
257 sample processing, and the data analysis methods (Fig 5B). Functional enrichment 258 analysis of the RNA-seq up-regulated genes (i.e., more expressed in MB than PB)

259 revealed processes involved with regulation of immune response, humoral immunity, 260 phagocytosis, cholesterol metabolism, complement activation among others (Fig 5C 261 and S9 Table). On the contrary, enrichment analysis of genes more expressed in PB 262 revealed biological processes such as leukocyte differentiation, lymphocyte 263 differentiation, lymphocyte-mediated immunity, B cell activation, STAT cascade 264 activation/regulation, and JAK-STAT cascade activation (Fig 5D and S10 Table), 265 which are consistent with exacerbated responses in granulomatous diseases. 266 Localized clinical forms, i.e., BT and TT, show a gene expression pattern indicative of 267 differentiation towards epithelioid transformation and granuloma assembly, which is 268 also observed in cutaneous or pulmonary sarcoidosis [36,37]. 
A

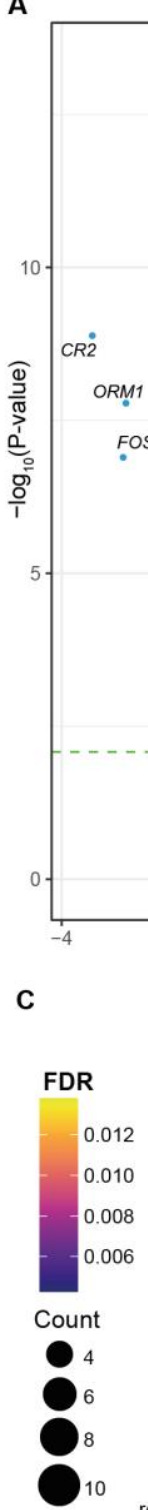

C

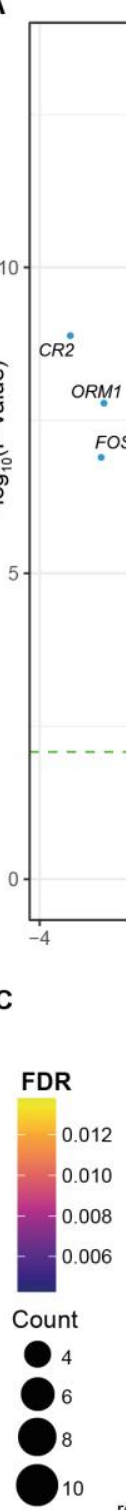

$\log _{2}$ (Fold change)

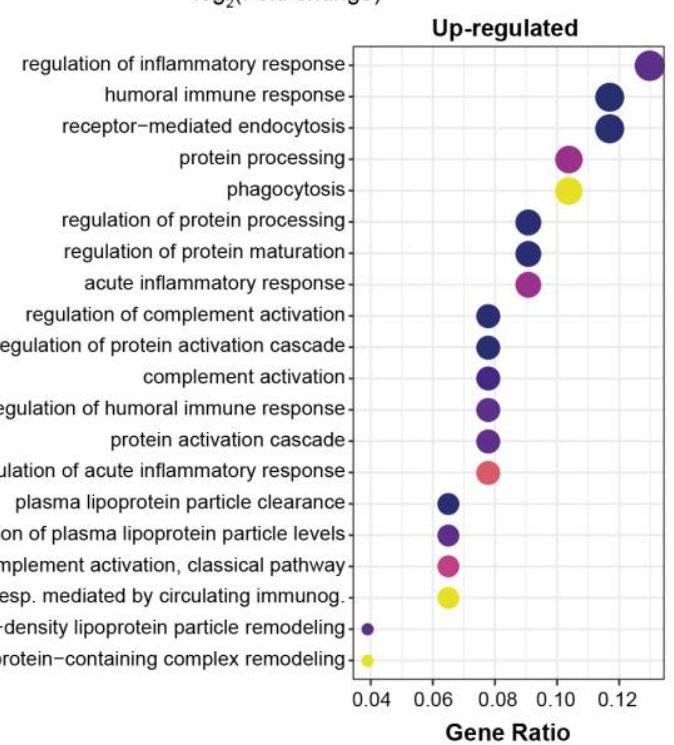

B

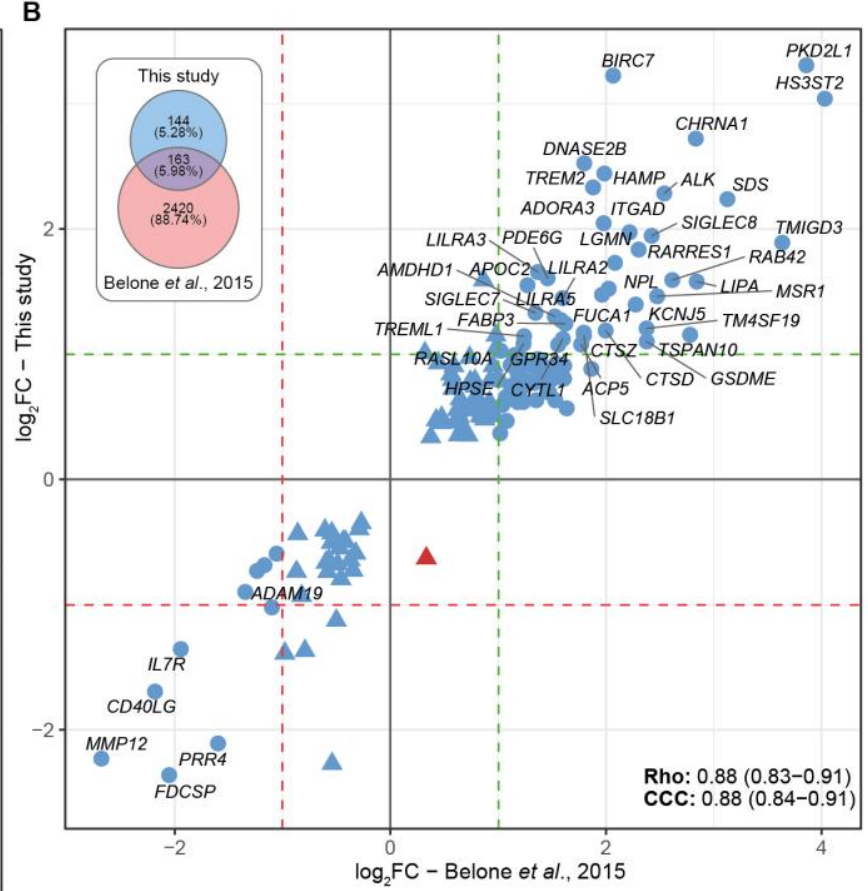

D
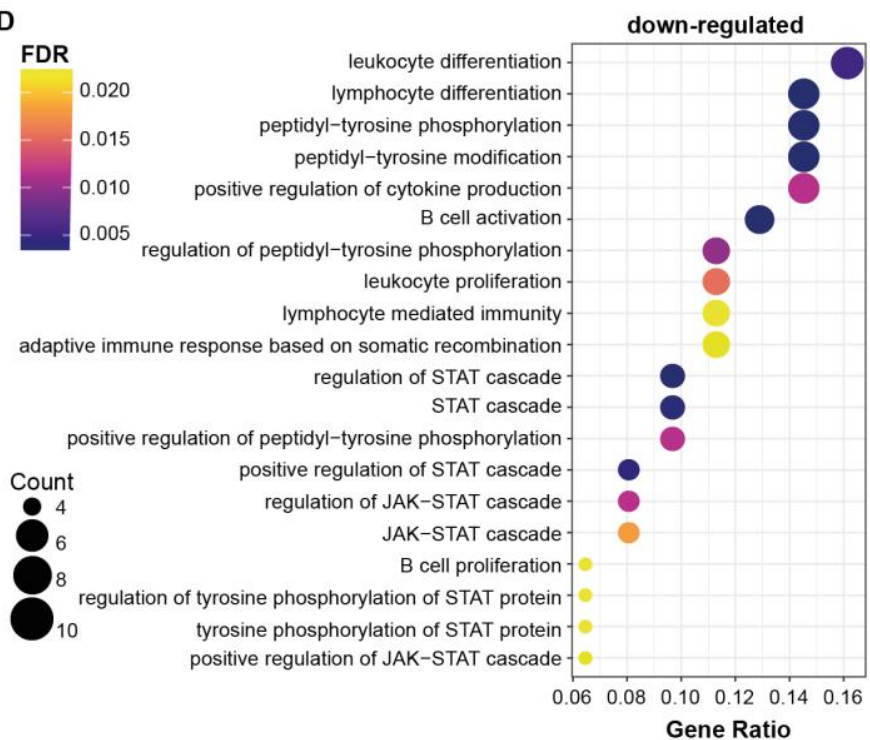

Fig 5. Differentially expressed genes from multibacillary (MB)

vs. paucibacillary

271 (PB) leprosy lesions. (A) Volcano plot showing DEG from the MB vs. PB comparison,

272 where blue points are DE with $\left|\log _{2} F C\right| \geq 1$ and FDR $<0.1$. (B) Scatter plots with the

273161 DEG common between this study and Belone et al. (24) microarray for the same

274 comparison. Red and green dashed lines indicate $\log _{2} \mathrm{FC}$ of -1 and 1 , respectively.

275 Blue points are genes with the same modulation signal and red indicates discordancy.

276 Rho, Spearman's rank correlation coefficient. CCC, Lin's concordance correlation 
277 coefficient. Venn diagram on the right displays the number of DEG in each study

278 according to FDR $<0.01$. (C) Biological processes from GO enriched from up-

279 regulated and (D) down-regulated DEG. FDR, false discovery rate.

280

281 Epithelial-mesenchymal transition (EMT) in the skin of 282 multibacillary leprosy patients

To make the most of our dataset, we sought to test a previous hypothesis generated from our group's microarray meta-analysis results, in which we have identified a consistent down-regulation of cornification, keratinocyte differentiation, and epidermal development-related genes in leprosy lesions, predominantly in MB [35]. We first hypothesized that such regulation could result from $M$. leprae inducing dedifferentiation of keratinocytes, similar to the phenomenon described previously in infected Schwann cells [38], and also seen in skin cancer by a process known as epithelial-mesenchymal transition (EMT) $[39,40]$. To test the hypothesis that such modulation was involved with EMT, we correlated the expression of the previously 292 identified down-regulated genes in leprosy [35] with a collection of genes involved with 293 previously Schwann cell dedifferentiation by M. leprae (Masaki et al. [38] signatures 294 for EMT and non-EMT genes), positive markers of EMT (from literature), as well as annotated EMT and mesenchymal-related genes from Reactome (R.HSA.452723, R.HSA.5619507.3, R.HSA.2173791) and Gene Ontology (G00001837) databases.

297 Briefly, the normalized $\log _{2}$ expression matrices were filtered to retain only genes of 298 interest. Then, the pairwise expression correlation for all genes was calculated using 299 the Spearman's rank correlation procedure. Finally, after adjusting the P-values for 
multiple testing, the genes with any pairwise correlation passing FDR $\leq 1 \times 10^{-4}$ and

301 rho $\leq-0.8$ were visualized using a heat plot. As result, with this study's RNA-seq, we

302 found a consistent moderate negative correlation between keratinization, cornification,

303 and epidermal development genes (Fig 6A, blue stars, AQP3, DMKN, DSG1, DSP,

304 EFNB2, JAG1, JAG2, KRT5, KRT10, KRT15, KRT19, OVOL2, PKP1, TACSTD2) with

305 those involved with canonical/alternative EMT and mesenchymal phenotypes (Fig 6A,

306 green stars, CTSZ, MMP9, PSAP, RHOA, TGFBR1, TGIF2, ZEB2, TGFB1).

307 Interestingly, the strongest correlations with epidermal/keratinocyte genes was with

308 TGF $\beta$-EMT-related genes (Fig. 6A blue block), as opposed to Masaki et al. non-EMT

309 and other mesenchymal/pluripotency pathways. Next, we replicated these

310 observations with Belone et al. microarray [24] and Montoya et al. RNA-seq datasets

311 [28], respectively. In Fig 6BC the strongest and representative correlations from

312 TGF $\square$-EMT-related pathway and a keratinocyte/epidermal gene signature are shown

313 in detail, while the remaining are available in Fig. S3-4.

Overall, these results showed a decreased expression pattern of EMT-related

genes in healthy skin samples, and a linear expression increase in $\mathrm{PB}$ and $\mathrm{MB}$

316 patients, especially with the microarray dataset, except for MMP9 (Fig 6C). This was

317 accompanied by the previously reduced expression of cytokeratins and epidermal

318 development genes observed in leprosy. From these results, we hypothesize that in

319 addition to TGF $\square$-dependent immunosuppression in MB patients, activation of this

320 pathway could be slowing or arresting keratinocyte cornification processes in leprosy

321 lesions thereby both facilitating survival and/or spread of $M$. leprae. If not involved with

322 dedifferentiation of keratinocytes or other epithelial cells, an alternative explanation

323 would be loss of epithelial barrier in MB patients, possibly enlightening a new M. leprae 
bioRxiv preprint doi: $h$ ttps://doi.org/10.1101/2021.07.30.454441; this version posted September 22, 2021. The copyright holder for this preprint (which was not certified by peer review) is the author/funder, who has granted bioRxiv a license to display the preprint in perpetuity. It is made available under aCC-BY-NC-ND 4.0 International license.

324 transmission route. Further mechanistic experiments ought to determine the causality

325 of our observations and test these findings in light of our hypothetical explanations of

326 the phenomenon.

327 
bioRxiv preprint doi: https://doi. org/10.1101/2021.07 30.454441; this version posted September 22, 2021. The copyright holder for this preprint (which was not certified by peer review) is the author/funder, who has granted bioRxiv a license to display the preprint in perpetuity. It is made available under aCC-BY-NC-ND 4.0 International license.

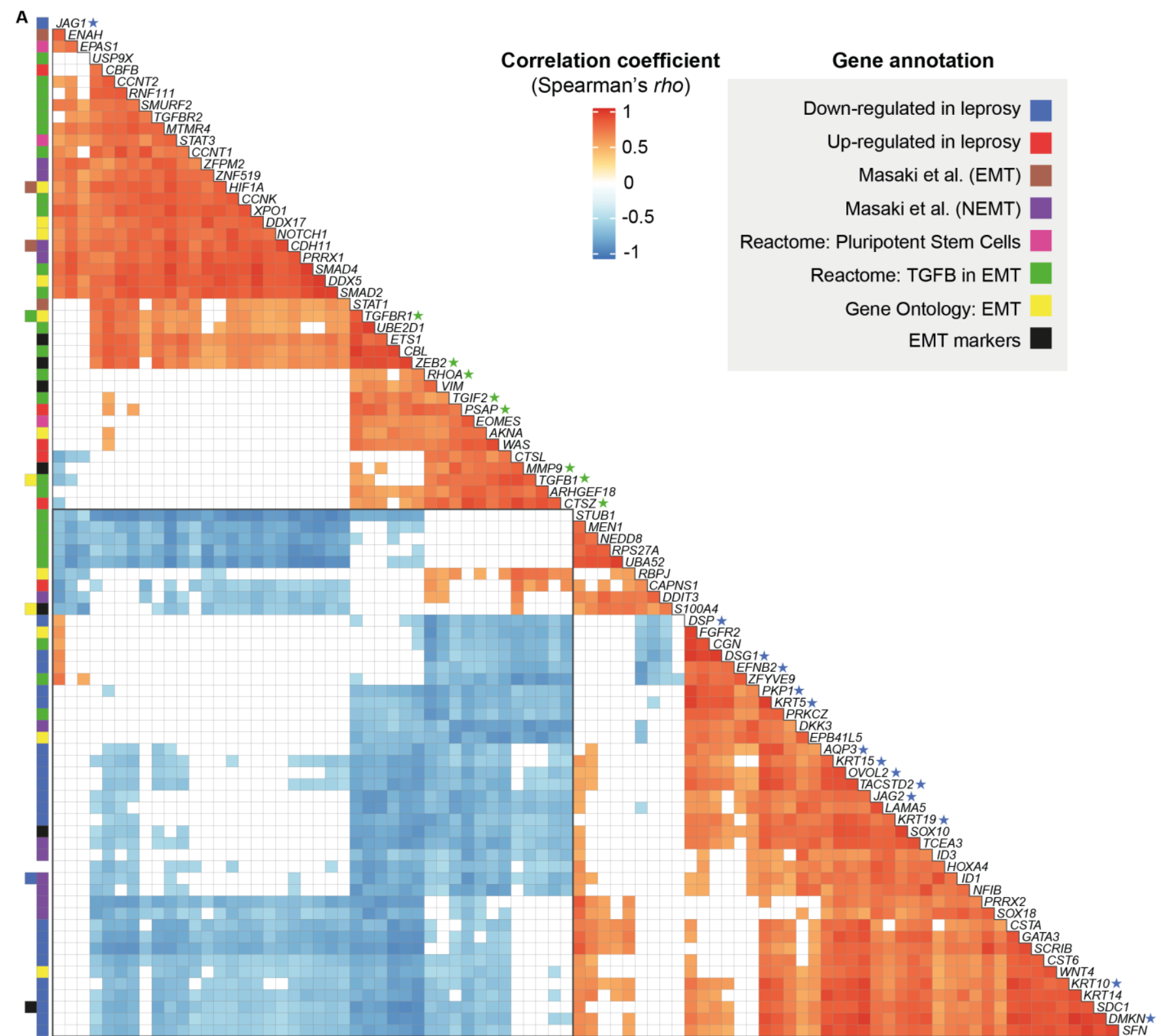

B
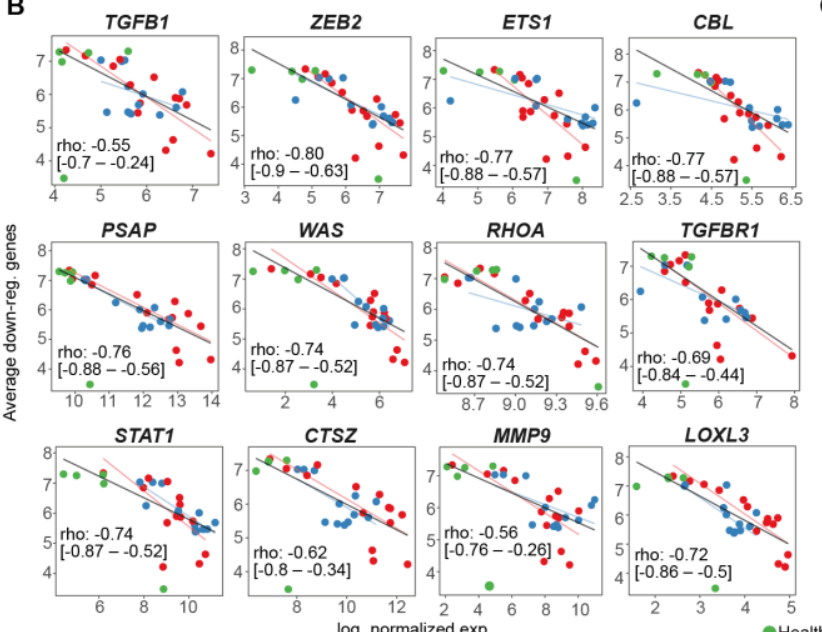

C
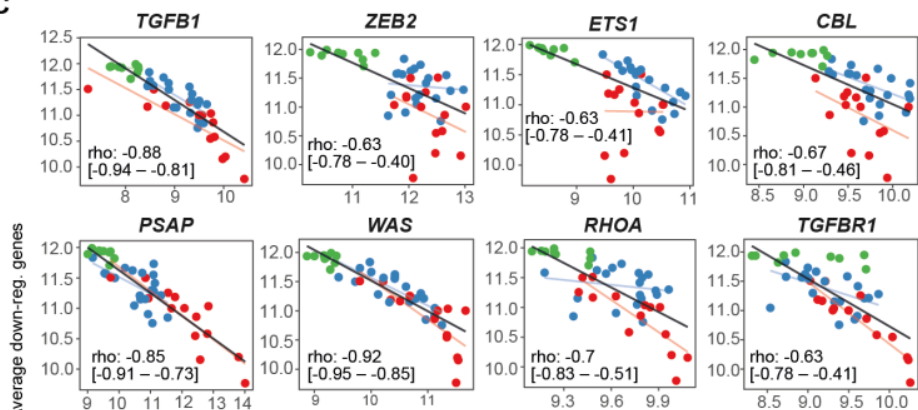

WAS

RHOA

TGFBR 1
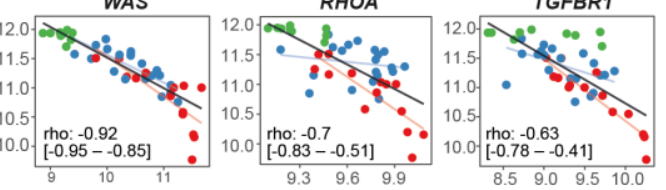

CTSZ

MMP9

LOXL3

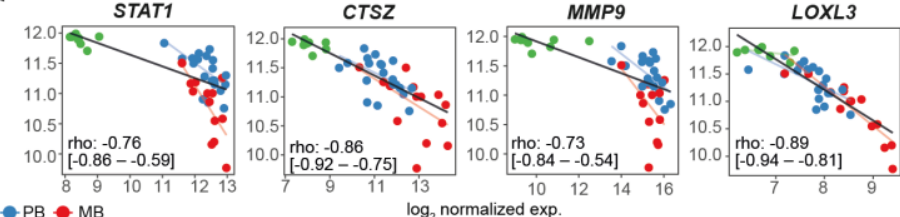

Fig 6. Strongest correlations between keratinocyte and EMT-related genes in 
329 leprosy lesions. (A) Heat plot with Spearman's rho correlation coefficient of the 330 strongest correlations after multiple testing adjustment with at least one gene-pair 331 passing FDR $\leq 0.0001$ and rho $\leq-0.8$. Correlations with FDR $>0.1$ are filled with white.

332 Row colored squares identify gene annotations. Scatter plots of average $\log _{2}$ 333 expression calculated with keratinocyte/epidermal development-related genes 334 previously documented as down-regulated in leprosy skin against dedifferentiationrelated genes using either (B) this study RNA-seq dataset or (C) Belone et al. microarray (GSE74481). Lines were drawn based on intercept and beta parameters estimated from robust linear regression for all samples (black line) or separately for 338 PB (blue line), and MB (red line). Spearman's rho coefficient along with 95\% nominal 339 confidence intervals are shown inside scatter plots calculated from all samples. See also S3 Fig and S4 Fig.

\section{Discussion}

One of the priorities in leprosy research is the development of reliable and accurate laboratory diagnosis tools for all leprosy forms to provide efficient treatment

344 and prevent disability [41]. This goal includes diagnosing patients with early forms of

345 the disease, those with low or mild apparent symptoms, thus assisting with ambiguous 346 differential diagnoses, and even classifying the disease for treatment (MB vs. PB) [4]. Host response to infection as measured by gene expression in skin biopsies

348 offers diagnostic, prognostic and predictive potential. By applying host transcriptomics

349 to skin lesions from leprosy patients and other common confounding dermatoses that 350 challenge clinicians and pathologists [9,30], we identified a small set of genes that provide a promising expression signature capable of distinguishing PB leprosy cases 
352 from other confounding dermatological diseases. The top candidate, IDO1, is a gene

353 involved in nutritional immunity and metabolism [42-45]. Alone, the expression of this

354 gene was able to differentiate leprosy from non-leprosy lesions with high accuracy in

355 our dataset and in others. According to the latest data from single-cell analysis [46],

356 IDO1 has been shown to be differentially expressed in Langerhans cells from leprosy

357 lesions compared to healthy skin, corroborating our findings. However, IDO1

358 expression is also increased in other mycobacterial diseases such as tuberculosis

$359[47,48]$, which might decrease its specificity. The accuracy of classification could be

360 improved by combining measurement of IDO1 expression with that of four other

361 biomarker genes BLK, CXCL11, CD38, TLR10 and SLAMF7, which also showed high

362 classification accuracy in the replication dataset. In parallel, the penalized logistic

363 regression model, evaluated on two independent datasets, demonstrated that

HS3ST2 and CD40LG hold potential to differentiate between MB and PB lesions. In

parallel, the penalized logistic regression model, evaluated on two independent

datasets, demonstrated that HS3ST2 and CD4OLGhold potential to differentiate

367 between MB and PB lesions. We recognize that there is no clinical utility in classifying

MB from PB lesions with laboratory assays because this can be done during

anamnesis alone. Hence, we aimed at identifying molecular features differing not only

in the measure of effect $\left(\log _{2} \mathrm{FC}\right)$ but also having little overlap between the lesion

371 types, as this may point to previously unexplored genes and pathways relevant to

372 future investigation. Considering the functional evidence for HS3ST2 [49], it is possible

373 that this gene may be involved with granuloma disassembly, tissue permeability, and

374 cellular migration in leprosy, which would explain its overexpression in MB lesions. On

375 the contrary, CD4OLG (also known as CD154) is more expressed in PB patients when

376 compared to MB with a predominant role in the activation of the microbicidal Th1 
response associated with PB lesions [50]. After mechanistic validation of our findings, quantifying expression levels of HS3ST2 and CD4OLG from leprosy lesions could be useful to assess immune responsiveness against $M$. leprae, help patient stratification and/or provide a basis for host-based adjuvant treatment for leprosy lesions. diagnosis is the cost of measuring a large number of genes and transforming these values into a unique continuous or binary classifier. So far, we were able to reproduce 384 the findings using both bulk RNA-sequencing and relative RT-qPCR, with the latter 385 being more accessible to clinicians at least in reference centers or central hospitals. 386 Although there are successful approved RT-qPCR relative gene expression-based diagnostic tests for diagnosing sepsis [12], clinical support for prostate [22], and breast cancer [18], there is a need for alternatives to reduce the cost and complexity of such assays. Quantification of mRNA based on isothermal amplification either with NASBA [51,52], RT-LAMP $[53,54]$ or CRISPR-Cas12 [55] is conceivable for less specialized settings without high-end equipment. Besides, combining a multi-target expressionbased diagnostic test with qPCR detection of $M$. leprae DNA could increase the specificity and sensitivity of leprosy diagnosis [56]. Alternatively, an ELISA assay measuring the levels of IDO1 protein from skin interstitial fluid, for example, could be proven useful [57]. Further studies ought to be done selecting tangible diagnostic 396 thresholds and devising a proper classification system to allow the biomarker to function unsupervised. pathogenesis has misled scientists for centuries $[5,6]$. Herein, we also compared the 400 two leprosy poles, MB and PB, and identified several pathways already known to be 
401 associated with leprosy, such as the humoral immune response, phagocytosis, and 402 complement activation. Genes involved with cholesterol and fatty acids were more 403 expressed in MB lesions, as already reported [58-60]. Interestingly, B-cell-related 404 genes were more expressed in PB than MB. In fact, it seems that both poles modulate 405 this pathway by a distinct set of genes. Involvement of B lymphocytes in PB leprosy 406 pathogenesis has been described by a few groups, which may indicate differential 407 involvement of such cells depending on the disease pole $[61,62]$.

M. leprae subverts host cell metabolism [63] by inducing lipid biosynthesis, 409 while avoiding type II (IFN-gamma) responses through a type I IFNs mechanism, 410 following the phagolysosomal breach that releases DNA into the cytosol [64]. 411 However, exactly how the bacilli spread throughout the body and bypass the 412 microbicidal immune response remains unknown. Here, we provide robust evidence 413 indicating that $M$. leprae may induce EMT in the skin within keratinocytes and 414 macrophages, as described in Schwann cells [38]. Indeed, M. leprae induced 415 dedifferentiation of infected Schwann cells into an immature stage resembling 416 progenitor/stem-like phenotype [38]. These reprogramming events induced by long417 term infection with $M$. leprae resulted in mesenchymal cells capable of migratory and 418 immune-permissive behavior, which in turn facilitated $M$. leprae spread to skeletal and 419 smooth muscles and furthered macrophage recruitment $[38,65]$. In our previous work, 420 we identified a down-regulated signature of keratinocyte differentiation and 421 cornification gene markers in MB skin lesions [35]. Here, we showed that such genes 422 are inversely correlated with genes involved with EMT, especially the members of the 423 TGF $\beta$-EMT pathway, such as TGFB1, TGFBR1, TGIF2, PSAP, ZEB2 [66,67]. Some 424 of these genes are directly or indirectly associated with EMT, such as a PSAP [68], 
WAS [69], RHOA [70-73], CTSZ [74], MMP9 [75], LOXL3 [76], HIF1A [77,78] among others.

Our hypothesis that $M$. leprae is inducing dedifferentiation or slowing the 428 cornification process in keratinocytes is plausible, given the evidence in Schwann cells 429 and a few reports of infection in this cell type (Fig 7) $[79,80]$. Nevertheless, other 430 phenomena could explain EMT's role in leprosy pathogenesis, such as wound healing 431 or loss of the epithelial barrier. Although, given its obligatory intracellular lifestyle, $M$. 432 leprae induces dedifferentiation in other cell types, either directly as in Schwann cells 433 or indirectly via chemokine and cytokine production in lesions. Besides inducing 434 keratinocyte dedifferentiation to mesenchymal cells, $M$. leprae might benefit from a decreased or alternative immune activation of these cells [81,82]. Further functional confirmatory experiments should elucidate the causality of this correlation and provide

437 definitive evidence of the relationship between the bacilli and other cell types, such as 438 keratinocytes, fibroblasts, and epithelial cells.

Our preliminary data also showed that the enriched pathways among PB skin

440 lesions were consistent with profiles observed in other granulomatous diseases, such 441 as noninfectious sarcoidosis and granuloma annulare, or chronic infectious diseases 442 like tuberculosis [37,83-85]. Our findings revealed that PB (TT/BT) lesions have, 443 among others, JAK-STAT cascade activation, which has been implicated in 444 sarcoidosis and GA. Remarkably, the JAK-STAT specific biological inhibitor, 445 tofacitinib, has a potent effect promoting rebalance of exacerbated immunity among 446 sarcoidosis and granuloma annulare patients reestablishing homeostasis [83]. 447 Another compound, everolimus, has been shown in experimental models to achieve 
448 the same response [37] suggesting that these drugs could be useful to treat PB, but 449 not MB, leprosy.

450 To conclude, our combined findings provide highly discriminatory mRNA 451 signatures from skin lesions that could distinguish leprosy from other dermatological 452 diseases and allow disease classification by monitoring only a handful of genes. In 453 addition, we report new genes and pathways that are likely informative regarding how

454 M. leprae interacts with and subverts host cells to promote its spread within the body 455 and subsequent transmission.

456 
bioRxiv preprint doi: https://doi org/10.1101/2021.0730.454441. this version posted September 22.2021 The copyright holder for this preprint (which was not certified by peer review) is the author/funder, who has granted bioRxiv a license to display the preprint in perpetuity. It is made available under aCC-BY-NC-ND 4.0 International license.

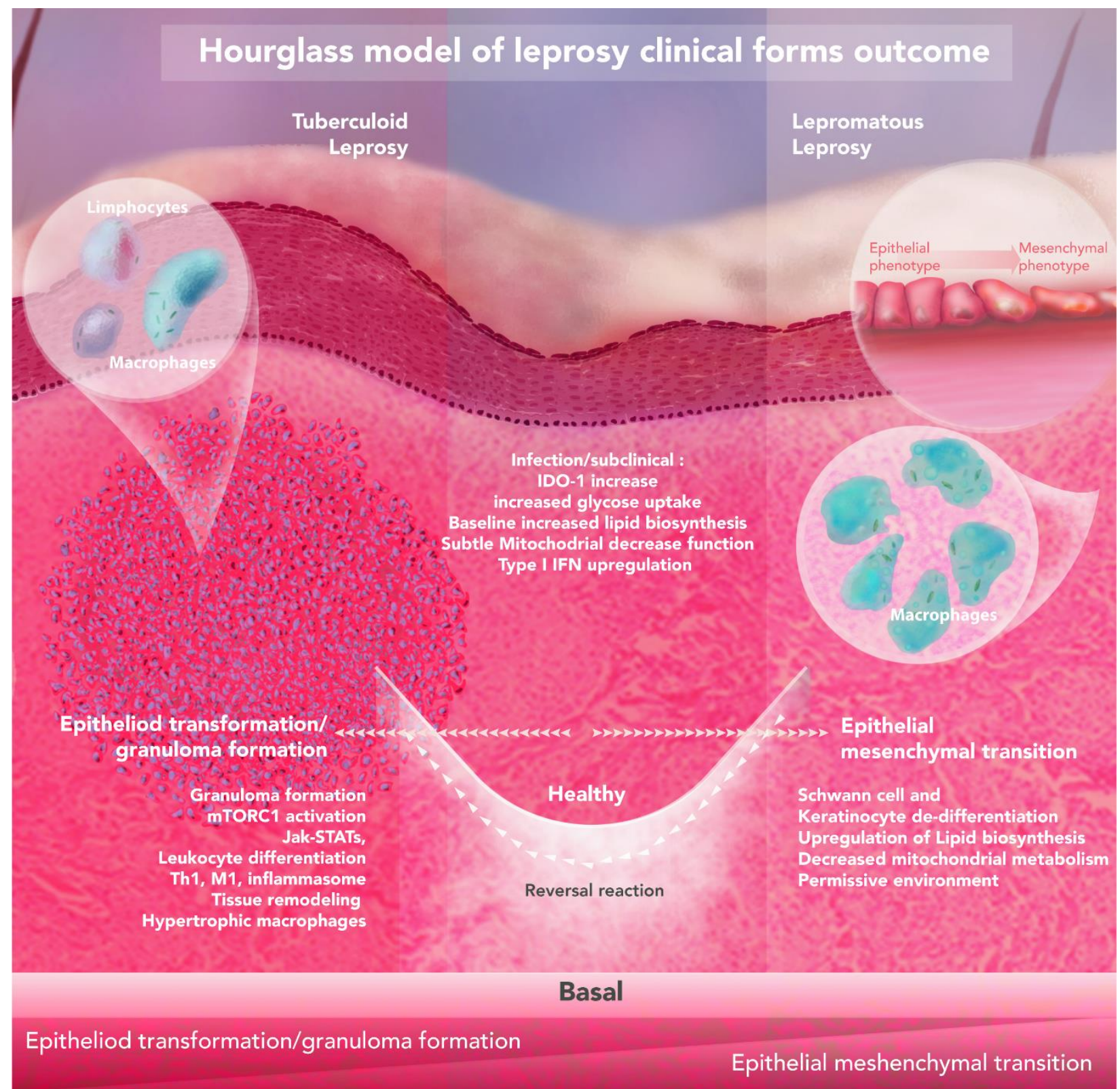

Fig 7. Hypothetical hourglass model contextualizing the observed findings for

459 leprosy clinical outcomes. The host-pathogen interaction in the skin leads to opposing leprosy clinical forms. Upon infection, $M$. leprae induces baseline metabolic alterations such as an increase in glucose uptake, modulation of lipid biosynthesis,

462 reduction of mitochondrial metabolism, and upregulation of IDO-1 and type I IFN.

463 Eventually, progression towards an unspecified inflammatory state can be observed

464 where three ways could be anticipated: I) self-healing; II) progression towards the 465 tuberculoid pole; or III) progression to lepromatous pole. These outcomes are driven 
466 by specific environmental and host genetic factors. It is expected that lower (or shorter)

467 M. leprae exposure, food shortage, BCG vaccination, and polymorphisms in genes

468 controlling autophagy/granuloma formation (NOD2, LRRK2, PRKM) all contribute to

469 developing leprosy per se. Excessive inflammation is one phenotype observed, that is

470 also seen in other granulomatous diseases (e.g., cutaneous sarcoidosis, granuloma 471 annulare), especially in paucibacillary lesions. On the other pole, epithelial-

472 mesenchymal transition and local immunosuppression are present due to a probably

473 higher (and/or longer) M. leprae exposure, combined with host single-nucleotide 474 polymorphisms (SNPs) at key genes, like lipid biogenesis (APOE) and central 475 metabolism (HIF1A, LACC1/FAMIN), culminating in disease progression.

\section{Materials and Methods}

\section{Patient cohort}

All patients were enrolled after informed written consent was obtained with approval from the Ethics Committee of the Oswaldo Cruz Foundation, number 151/01.

480 Leprosy clinical forms were classified according to the criteria of Ridley and Jopling 481 [2]. Leprosy patients were treated according to the operational criteria established by 482 the World Health Organization [4]. Leprosy and patients with other dermatological 483 diseases were eligible if their diagnosis was confirmed by clinical and histopathological 484 findings. Additionally, detection of $M$. leprae DNA by qPCR routinely performed in our 485 laboratory could be employed to support diagnosis $[56,86]$. HIV and hepatitis B 486 positive patients were not included in this study, in addition, we excluded individuals 487 with a current or previous history of tuberculosis. No other comorbidities were used to 
exclude patients and further individual information is available in S1 Table. Skin biopsy specimens containing both epidermis and dermis were obtained with $3 \mathrm{~mm}$ (diameter) sterile punches following local anesthesia from the lesion site. Skin biopsies were

491 immediately stored in one milliliter of RNALater (Ambion, Thermo Fisher Scientific Inc.,

492 MA, USA) according to the manufacturer's instructions and stored in liquid nitrogen 493 until RNA isolation. Healthy skin biopsies were from lesion-free sites of patients 494 diagnosed with indeterminate or pure neural leprosy.

495

\section{Study Design}

The main objective of this research was to identify host gene expression 497 patterns capable of distinguishing leprosy (including the PB forms) from other 498 differential diagnosis of skin lesions. Our working hypothesis was that leprosy lesions, despite their morphological and histopathological similarity to other skin diseases, may

500 induce distinct patterns of gene expression in at a small subset. We predefined the 501 comparison of leprosy (PB+MB) from non-leprosy including GA in addition to healthy 502 patients for RNA sequencing experiment. In addition, we predetermined comparisons 503 between leprosy poles: MB vs. PB. Our samples are representative of a population of 504 individuals attending the Sousa Araujo Outpatient Clinic based in Rio de Janeiro, 505 Brazil, which also receives patients from surrounding municipalities.

\section{RNA isolation}

Snap frozen skin biopsies were thawed in wet ice and processed using TRIzol

508 Reagent (Ambion, Thermo Fisher Scientific Inc., MA, USA) according to the manufacturer's instructions with the help of Polytron Homogenizer PT3100 
510 (Kinematica AG, Switzerland). RNA was treated with DNAse using the DNAfree kit

511 (Thermo Fisher Scientific Inc., MA, USA) according to the standard manufacturer's

512 protocol, prior to use for library preparation and RT-qPCR. RNA integrity was

513 assessed in 1\% agarose gel electrophoresis or TapeStation RNA ScreenTape (Agilent

514 Technology, CA, USA). During RNA isolation, samples were randomly assigned to

515 extraction batches and freeze-thaw cycles to minimize batch effects and the

516 introduction of technical artifacts. All procedures applied to samples were carried out

517 using reagents from the same lot. The first author conducted the experiments aware

518 of each sample group during the entire process, therefore, no blinding scheme was

519 used, although we do not rely on perceptual/abstract measurements or analyses nor

520 did we purposefully exclude samples.

521 Library preparation and Illumina RNA sequencing

RNA-seq libraries were prepared with $1 \mu \mathrm{g}$ of total RNA for each sample using

523 the Illumina TruSeq mRNA kit (Illumina, USA) as recommended by the manufacturer

524 using the Illumina CD RNA indexes (Illumina, USA). Libraries were quantified and 525 qualified using a qPCR quantification protocol guide (KAPA Library Quantification Kits 526 for Illumina Sequencing platforms) and TapeStation D1000 ScreenTape (Agilent

527 Technologies, USA), respectively. The resulting libraries (fragment size 200-350bp)

528 were multiplexed (17, 17, and 19 libraries, respectively) and sequenced using the 529 NextSeq 500 platform (Illumina, USA), generating approximately 520 million single530 end reads of 75 nucleotides in length. 
531 RNA-sequencing analysis

RAW bcl files were converted into .fastq using Illumina's bcl2fastq script. Then,

533 read quality was assessed using FastQC version 0.11 .8 [87]. Next, transcript counts

534 were estimated using Salmon (v.1.13.0) quasi-mapping (human transcriptome

535 GRCh38_cdna sourced from Ensembl/RefGenie plus pre-computed salmon index,

536 http://refgenomes.databio.org/\#hg38_cdna) with default settings and --seqBias flag

537 set [88]. Transcript counts were summarized into ENSEMBL gene counts using the $R$

538 v.3.6.1 package tximport v.1.12.0 [89,90] and biomaRt v.2.40.5 [91]. The expression

539 of sex-chromosome-specific genes, such as UTY and XIST, was used to rule out

540 sample mislabeling. Differential expression was estimated using DESEq2 v.1.24.0,

541 after filtering out weakly expressed genes with less than 10 counts per million and less

542 than 15 total counts in $70 \%$ of samples [92-94]. In addition to the patient's biological

543 sex, extraction batch and sequencing run, three surrogate variables estimated with

544 RUVseq v.1.18.0 were included in DESeq2's generalized linear model [95,96].

545 Nominal P-values were inspected with histograms and adjusted for multiple testing

546 according to the method [97] proposed for controlling the false discovery rate (FDR).

547 All $\log _{2}$ fold-changes were shrunken prior to DE filtering with the apeglm [94] or normal

548 algorithms. For visualization, counts per million (CPM) were computed with edgeR's

549 cpm function v.3.26.1 and variance stabilized with the parametric method [92]. Then,

550 surrogate variables and covariates were regressed out from the expression matrix

551 using limma's removeBatchEffect [98-100] before being visualized with ggplot2

552 v.3.3.0 [101]. Hierarchical clustering, heatmaps, and ROC analysis were all performed

553 with the previously processed expression matrix. Heatmap with hierarchical clustering

554 was drawn with ComplexHeatmap v.2.0.0 [102] or pheatmap v.1.0.12 [103] using 
555 gene-wise scaled and centered matrix with Euclidean distance and average

556 agglomeration method. Overrepresentation analysis (ORA) was used to test for Gene

557 Ontology Biological Process (GO BP) enrichment with clusterProfiler v.3.12.0 [104]

558 and org.Hs.eg.db v.3.8.2 annotations [105]. Up and down-regulated lists were used as

559 inputs and the background list was composed of all genes subjected to differential

560 expression. P-values were adjusted for multiple testing using the Benjamini-Hochberg

561 method [97]. Raw and normalized RNA sequencing data are available in EMBL-EBI's

562 ENA and ArrayExpress under accessions ERP128243 and E-MTAB-10318,

563 respectively.

\section{RT-qPCR}

A total of $2.5 \mu \mathrm{g}$ of RNA was reversed transcribed into cDNA using $4 \mu \mathrm{L}$ of Vilo

Master Mix (Thermo Fisher Scientific Inc., USA) according to the manufacturer's

567 instructions. Then, cDNA was diluted to a final concentration of $5 \mathrm{ng} / \mu \mathrm{L}$ using TE buffer

568 (10 mM Tris-HCL and $0.1 \mathrm{mM}$ EDTA in RNAse-free water). RT-qPCR was performed

569 using Fast Sybr Master Mix (Thermo Fisher Scientific Inc., USA) in a final reaction

570 volume of $10 \mu \mathrm{L}$. For each reaction, performed in duplicate, $5 \mu \mathrm{L}$ of Fast Sybr Green

571 were combined with $200 \mathrm{nM}$ of each primer, $10 \mathrm{ng}$ of cDNA, and q.s.p of injection-

572 grade water. Thermal cycling and data acquisition were performed on Viia7 with 384

573 well block (Applied Biosystems, Thermo Fisher Scientific Inc., USA) following the

574 master mix manufacturer cycling preset with a final melting curve analysis $\left(65{ }^{\circ} \mathrm{C}\right.$ to

$57595^{\circ} \mathrm{C}$, captured at every $0.5^{\circ} \mathrm{C}$ ). All primers were designed with NCBI Primer-Blast

576 [106-109] to either flank intron(s) or span exon-exon junction(s) to avoid gDNA

577 amplification (S11 Table). Further, primers were quality checked for specificity, dimers 
578 and hairpin with MFEPrimer v.3.0 [110,111] and IDT's oligoAnalyzer

579 (https://www.idtdna.com/calc/analyzer). Data were exported from QuantStudio

580 software v.1.3 in RDML format, which was imported to LinRegPCR v.2020.0 for RT-

581 qPCR efficiency determination and calculation of the $\mathrm{N}_{0}$ value $[112,113]$. Finally, $\mathrm{N}_{0}$

582 values were imported to $\mathrm{R}$ and normalized using as the denominator the normalization

583 factor (NF) calculated from the geometric mean of at least three reference genes

584 (RPS16, RPL35 and QRICH1), which were previously tested for stability [114]. These

585 No normalized values were used for visualization in Fig 2A. For mean difference

586 estimation between groups, RT-qPCR data were analyzed in a Bayesian framework

587 (Markov Chain Monte Carlo sampling, MCMC) using generalized linear mixed effect

588 models under lognormal-Poisson error with MCMC.qpcr v.1.2.4 [115,116]. Per-gene

589 efficiency estimates from LinRegPCR were used in conjunction with Cp (crossing

590 point) calculated in QuantStudio software v.1.3 to generate the counts table. Then, the

591 generalized linear mixed-effect model was fitted using three reference genes (allowing

592 up to $20 \%$ between-group variation) with 550,000 iterations, thin $=100$, and burn-in of

59350,000 . The model specification included the sample (factor with 51 levels) as a 594 random effect and the diagnosis group (factor with 3 levels) as a fixed effect. MCMC

595 diagnostics were done by inspecting chain mixing plots and linear mixed model 596 diagnostic plots. Ninety-five percent credible intervals were drawn around the posterior 597 means and MCMC equivalent P-values were also computed.

\section{Reanalysis of public gene expression datasets}

Belone and collaborators GSE74481 [24] and de Toledo-Pinto and cols.

600 GSE35423 [64] microarray datasets were reanalyzed as described elsewhere [35].

601 Blischak and cols. [32] RNA-seq dataset (GSE67427) was reanalyzed from counts per 
sample file from the author's Bitbucket repository (https://bitbucket.org/jdblischak/tb-

604 RNA integrity number and extraction batch variables. Then, differences in gene 605 expression (48h post-infection) for specific genes and treatments were tested using a 606 gene-wise linear mixed model with a random intercept per sample (replicate) followed 607 by Dunnet comparison against a "mock" group using emmeans v.1.5.3. Montoya and 608 collaborators' dataset was retrieved from GEO (GSE125943) already normalized 609 (DESeq2 median ratio method) and transformed with base 2 logarithm with no further 610 processing [28].

\section{Correlation analyses}

For RNA-seq datasets, normalized $\log _{2}$ counts-per-million values were used and $\log _{2}$ normalized intensities for microarray. Spearman's rank correlation method

614 was chosen because it is robust against outliers, does not rely on normality 615 assumption, and also identifies monotonic but non-linear relationships. Initially, a list 616 of keratinocyte/cornification/epidermal development genes that were DE in the meta617 analysis was assembled [35]. Then, lists of target genes were compiled from results 618 of Masaki et al. [38]: EMT and non-EMT; from Reactome: R-HSA-452723 619 (Transcriptional regulation of pluripotent stem cells), R-HAS-5619507.3 (Activation of 620 HOX genes during differentiation), R-HAS-2173791 (TGF $\beta$ receptor signaling in EMT); 621 Gene Ontology GO:0001837 (EMT), and literature for EMT canonical markers. Next 622 pairwise Spearman correlation was calculated using the Hmisc's rcorr function v.4.26230 for every pair of genes from keratinocyte/epidermal development and EMT gene 624 lists. P-values were adjusted for multiple testing using the $\mathrm{BH}$ method for FDR control 
625 for all tests [97]. Additionally, 95\% nominal confidence intervals were calculated using

626 the Fieller method implemented by correlation R package v.0.5.0 [117,118]. To

627 visualize the results, only genes with at least one pairwise correlation with Spearman's

628 rho coefficient $\leq-0.8$ and FDR $\leq 0.0001$ were selected. Additionally, the average $\log _{2}$

629 expression from genes involved with keratinocyte/epidermal development was

630 calculated and used in scatter plots against the expression of the EMT genes. Scatter

631 plots were drawn with ggplot2 v.3.3.3 showing lines from coefficients estimated using

632 default robust regression (MASS::rlm v.7.3-51.4) either for all samples or stratified by

633 group. No outliers were omitted.

634 Regularized (LASSO) logistic regression classification

Normalized $\log _{2}$ expression matrices regressed out for covariates and batches

were used as input predictors. The model was trained using the microarray dataset

637 from Belone et al. [24] with penalized regression (L1-norm, LASSO) and 4-fold cross-

638 validation ( $\mathrm{k}$-fold $\mathrm{CV}$ ) with the negative binomial log-likelihood link function, glmnet

639 v.4.1 [119-121]. Predictors were standardized to have mean zero and unit variance

640 inside the cv.glmnet function. We opted for L1-norm because it results in a smaller

641 number of genes (\#features $\leq \mathrm{n}$ ) with non-zero coefficients, as compared to elastic-

642 net or ridge regression counterparts. In addition, this model is suitable for high-

643 dimensional data as it combines feature selection during model tuning and training,

644 mitigating the effects of predictors' collinearity and reducing overfitting. To assess the

645 coefficients' error, misclassification error rate, feature stability and model size we used

646 non-parametric bootstrap (boot v.1.3.25) with 10,000 samples, with 4-fold cross-

647 validation inside each loop [122,123]. The final LASSO model selected by 4 -fold cross- 
648 validation contained three non-zero genes. Finally, independent RNA-seq test

649 datasets were used to compute the accuracy of the final model. Alternatively, the

650 whole process was repeated with leave-one-out cross-validation instead of k-fold. The

651 results were practically indistinguishable, especially regarding the feature stability

652 (data not shown).

\section{Sample sizes}

The sample size for RNA sequencing was selected based on previous leprosy

work with microarrays, aiming at detecting genes with at least a differential fold-change

of two. For RT-qPCR validation, sample size calculation was performed using the per-

657 gene standardized effect size estimated from the RNA-seq data, aiming at a power of

$65885 \%$ and alpha $=0.03$. No samples were discarded after successful data collection

659 (i.e. outliers). In the end, the sample sizes per group for RT-qPCR were: MB = 14,

$660 \mathrm{~PB}=11, \mathrm{ODD}=23$. All $\mathrm{RT}-\mathrm{qPCR}$ reactions were conducted in duplicate for each

661 biological unit (here, a fragment of a skin biopsy derived from an individual).

\section{RT-qPCR and ROC statistical analyses}

Normalized RT-qPCR gene expression data were $\log _{2}$ transformed before use

664 in data visualization. Additionally, we checked if the Bayesian results remained 665 consistent using a more common procedure (data not shown). For this, the mean 666 normalized expression (from No) was compared pairwise for the prior stipulated groups 667 using Welch's t-test implemented in R language, using the predetermined alpha of 668 0.03. Normality assumption was verified with normal quantile-quantile plots (qqplots, 
car v. 3.0-2). In cases where quantile-quantile plots showed huge deviation from theoretical normal distribution, the Wilcoxon Rank Sum was used to verify results.

672 (measured by the area under the curve, AUC) and its respective best classification

673 threshold, aiming at maximizing AUC with equal importance for sensitivity and 674 specificity. Confidence intervals (95\%) for AUC were calculated using the Delong non675 parametric method as implemented in pROC v.1.15.3 [124-126].

\section{Data and code reporting} database (ERP128243). Raw Salmon counts and normalized batch cleaned

679 expression matrices are available in EMBL-EBI ArrayExpress, under E-MTAB-10318, 680 along with experimental and phenotypic metadata. $R$ source code and accompanying 681 intermediate data used in all analyses in this manuscript are also readily available 682 through Zenodo, doi.org/10.5281/zenodo.4682010.

\section{Acknowledgements}


691 References

692 1. Britton WJ, Lockwood DN. Leprosy. The Lancet. 2004;363: 1209-1219.

693 doi:10.1016/S0140-6736(04)15952-7

694 2. Ridley DS, Jopling WH. Classification of leprosy according to immunity. A five695 group system. Int J Lepr Mycobact Dis Off Organ Int Lepr Assoc. 1966;34: 255-73.

696 3. Scollard DM, Adams LB, Gillis TP, Krahenbuhl JL, Truman W, Williams DL.

697 The Continuing Challenges of Leprosy The Continuing Challenges of Leprosy. Clin

698 Microbiol Rev. 2006;19: 338-381. doi:10.1128/CMR.19.2.338

699 4. WHO. Guidelines for the Diagnosis, Treatment and Prevention of Leprosy.

700 Geneva: World Health Organization; 2018 p. 106.

701 5. WHO. Global leprosy (Hansen disease) update, 2019: time to step-up

702 prevention initiatives. Wkly Epidemiol Rec. 2020;95: 417-440.

7036 6ath I, Saini C, Valluri VL. Immunology of leprosy and diagnostic challenges.

704 Clin Dermatol. 2015;33: 90-98. doi:10.1016/j.clindermatol.2014.07.005

705 7. van Hooij A, Tjon Kon Fat EM, Batista da Silva M, Carvalho Bouth R, Cunha 706 Messias AC, Gobbo AR, et al. Evaluation of Immunodiagnostic Tests for Leprosy in

707 Brazil, China and Ethiopia. Sci Rep. 2018;8: 1-9. doi:10.1038/s41598-018-36323-1

708 8. van Hooij A, van den Eeden S, Richardus R, Tjon Kon Fat E, Wilson L,

709 Franken KLMC, et al. Application of new host biomarker profiles in quantitative point-

710 of-care tests facilitates leprosy diagnosis in the field. EBioMedicine. 2019;47: 301-

711 308. doi:10.1016/j.ebiom.2019.08.009 
712 9. Manta FS de N, Leal-Calvo T, Moreira SJM, Marques BLC, Ribeiro-Alves M,

713 Rosa PS, et al. Ultra-sensitive detection of Mycobacterium leprae: DNA extraction

714 and PCR assays. Poonawala H, editor. PLoS Negl Trop Dis. 2020;14: e0008325.

715 doi:10.1371/journal.pntd.0008325

716 10. Gliddon HD, Herberg JA, Levin M, Kaforou M. Genome-wide host RNA

717 signatures of infectious diseases: discovery and clinical translation. Immunology.

718 2018;153: 171-178. doi:10.1111/imm.12841

719 11. Ko ER, Yang WE, McClain MT, Woods CW, Ginsburg GS, Tsalik EL. What

720 was old is new again: Using the host response to diagnose infectious disease.

721 Expert Rev Mol Diagn. 2015;15: 1143-1158. doi:10.1586/14737159.2015.1059278

722 12. Miller RR, Lopansri BK, Burke JP, Levy M, Opal S, Rothman RE, et al.

723 Validation of a host response assay, SeptiCyte LAB, for discriminating sepsis from

724 systemic inflammatory response syndrome in the ICU. Am J Respir Crit Care Med.

725 2018;198: 903-913. doi:10.1164/rccm.201712-2472OC

726 13. Van Hooij A, Fat EMTK, Van Den Eeden SJF, Wilson L, Da Silva MB,

727 Salgado CG, et al. Field-friendly serological tests for determination of M. Leprae-

728 specific antibodies. Sci Rep. 2017;7: 1-8. doi:10.1038/s41598-017-07803-7

729 14. Warsinske H, Vashisht R, Khatri P. Host-response-based gene signatures for

730 tuberculosis diagnosis: A systematic comparison of 16 signatures. PLoS Med.

$731 \quad 2019 ; 16$. doi:10.1371/journal.pmed.1002786

732 15. Röltgen K, Pluschke G, Spencer JS, Brennan PJ, Avanzi C. The immunology

733 of other mycobacteria: M. ulcerans, M. leprae. Semin Immunopathol. 2020;42: 333-

734 353. doi:10.1007/s00281-020-00790-4 
735 16. Mesko B, Poliska S, Nagy L. Gene expression profiles in peripheral blood for

736 the diagnosis of autoimmune diseases. Trends Mol Med. 2011;17: 223-233.

737 doi:10.1016/j.molmed.2010.12.004

738 17. Wang B, Chen S, Zheng Q, Gao Z, Chen R, Xuan J, et al. Development and 739 initial validation of diagnostic gene signatures for systemic lupus erythematosus. Ann

740 Rheum Dis. 2019. doi:10.1136/annrheumdis-2019-216695

741 18. Carlson JJ, Roth JA. The impact of the Oncotype Dx breast cancer assay in

742 clinical practice: A systematic review and meta-analysis. Breast Cancer Res Treat.

743 2013;141: 13-22. doi:10.1007/s10549-013-2666-z

744 19. Gordon GJ, Jensen RV, Hsiao LL, Gullans SR, Blumenstock JE, Ramaswamy

745 S, et al. Translation of microarray data into clinically relevant cancer diagnostic tests

746 using gene expression ratios in lung cancer and mesothelioma. Cancer Res.

$747 \quad 2002 ; 62:$ 4963-4967.

748 20. Narrandes S, Xu W. Gene expression detection assay for cancer clinical use.

749 J Cancer. 2018;9: 2249-2265. doi:10.7150/jca.24744

750 21. Clark-Langone KM, Sangli C, Krishnakumar J, Watson D. Translating tumor

751 biology into personalized treatment planning: analytical performance characteristics

752 of the Oncotype DX®Colon Cancer Assay. BMC Cancer. 2010;10: 691.

753 doi:10.1186/1471-2407-10-691

754 22. Knezevic D, Goddard AD, Natraj N, Cherbavaz DB, Clark-Langone KM,

755 Snable J, et al. Analytical validation of the Oncotype DX prostate cancer assay - a

756 clinical RT-PCR assay optimized for prostate needle biopsies. BMC Genomics.

757 2013;14: 1-12. doi:10.1186/1471-2164-14-690 
758

759

760

761

762

763

764

765

766

767

768

769

770

771

772

773

774

775

776

777

778

779

780

23. Laible M, Schlombs K, Kaiser K, Veltrup E, Herlein S, Lakis S, et al. Technical validation of an RT-qPCR in vitro diagnostic test system for the determination of breast cancer molecular subtypes by quantification of ERBB2, ESR1, PGR and MKI67 mRNA levels from formalin- fixed paraffin-embedded breast tumor specimens. BMC Cancer. 2016; 1-14. doi:10.1186/s12885-016-2476-x

24. Belone A de FF, Rosa PS, Trombone APF, Fachin LRV, Guidella CC, Ura S, et al. Genome-wide screening of mRNA expression in leprosy patients. Front Genet. 2015;6: 1-12. doi:10.3389/fgene.2015.00334

25. Jorge KTOS, Souza RP, Assis MTA, Araújo MG, Locati M, Jesus AMR, et al. Characterization of MicroRNA Expression Profiles and Identification of Potential Biomarkers in Leprosy. J Clin Microbiol. 2017;55: 1516-1525. doi:10.1128/JCM.02408-16

26. Tió-Coma M, van Hooij A, Bobosha K, van der Ploeg-van Schip JJ, Banu S, Khadge S, et al. Whole blood RNA signatures in leprosy patients identify reversal reactions before clinical onset: a prospective, multicenter study. Sci Rep. 2019;9: 17931. doi:10.1038/s41598-019-54213-y

27. Tió-Coma M, Kiełbasa SM, van den Eeden SJF, Mei H, Roy JC, Wallinga J, et al. Blood RNA signature RISK4LEP predicts leprosy years before clinical onset. EBioMedicine. 2021;68: 103379. doi:10.1016/j.ebiom.2021.103379

28. Montoya DJ, Andrade P, Silva BJA, Teles RMB, Ma F, Bryson B, et al. Dual RNA-Seq of Human Leprosy Lesions Identifies Bacterial Determinants Linked to Host Immune Response. Cell Rep. 2019;26: 3574-3585.e3.

doi:10.1016/j.celrep.2019.02.109 
781 29. Bhatia S, Shenoi SD, Pai K, Srilatha PS. Granuloma multiforme: an

782 uncommon differential for leprosy. Trop Doct. 2019;49: 55-58.

783 doi: $10.1177 / 0049475518803191$

784 30. Kundakci N, Erdem C. Leprosy: A great imitator. Clin Dermatol. 2019;37:

785 200-212. doi:10.1016/j.clindermatol.2019.01.002

786 31. Zhu TH, Kamangar F, Silverstein M, Fung MA. Borderline Tuberculoid

787 Leprosy Masquerading as Granuloma Annulare: A Clinical and Histological Pitfall.

788 Am J Dermatopathol. 2017;39: 296-299. doi:10.1097/DAD.0000000000000698

789 32. Blischak JD, Tailleux L, Mitrano A, Barreiro LB, Gilad Y. Mycobacterial

790 infection induces a specific human innate immune response. Sci Rep. 2015;5: 1-16.

791 doi:10.1038/srep16882

792 33. Modlin RL. Th1-Th2 paradigm: insights from leprosy. J Invest Dermatol.

793 1994;102: 828-832. doi:10.1111/1523-1747.ep12381958

794 34. Yamamura M, Uyemura K, Deans RJ, Weinberg K, Rea TH, Bloom BR, et al.

795 Defining protective responses to pathogens: Cytokine profiles in leprosy lesions.

796 Science. 1991;254: 277-279. doi:10.1126/science.1925582

797 35. Leal-Calvo T, Moraes MO. Reanalysis and integration of public microarray

798 datasets reveals novel host genes modulated in leprosy. Mol Genet Genomics.

799 2020;295: 1355-1368. doi:10.1007/s00438-020-01705-6

800 36. Judson MA, Marchell RM, Mascelli M, Piantone A, Barnathan ES, Petty KJ, et

801 al. Molecular profiling and gene expression analysis in cutaneous sarcoidosis: the

802 role of interleukin-12, interleukin-23, and the T-helper 17 pathway. J Am Acad

803 Dermatol. 2012;66: 901-910, 910.e1-2. doi:10.1016/j.jaad.2011.06.017 
804 37. Linke M, Pham HTT, Katholnig K, Schnöller T, Miller A, Demel F, et al.

805 Chronic signaling via the metabolic checkpoint kinase mTORC1 induces

806 macrophage granuloma formation and marks sarcoidosis progression. Nat Immunol.

807 2017;18: 293-302. doi:10.1038/ni.3655

808 38. Masaki T, Qu J, Cholewa-Waclaw J, Burr K, Raaum R, Rambukkana A.

809 Reprogramming adult Schwann cells to stem cell-like cells by leprosy bacilli

810 promotes dissemination of infection. Cell. 2013;152: 51-67.

811 doi:10.1016/j.cell.2012.12.014

812 39. Brabletz T, Kalluri R, Nieto MA, Weinberg RA. EMT in cancer. Nat Rev

813 Cancer. 2018;18: 128-134. doi:10.1038/nrc.2017.118

814 40. Pastushenko I, Blanpain C. EMT Transition States during Tumor Progression 815 and Metastasis. Trends Cell Biol. 2019;29: 212-226. doi:10.1016/j.tcb.2018.12.001

816 41. Khazai Z, Van Brakel W, Essink D, Gillis T, Kasang C, Kuipers P, et al.

817 Reviewing Research Priorities of the Leprosy Research Initiative (LRI): a

818 stakeholder's consultation. Lepr Rev. 2019;90: 3-30. doi:10.47276/lr.90.1.3

819 42. Chen W. IDO: more than an enzyme. Nat Immunol. 2011;12: 809-811.

820 doi:10.1038/ni.2088

821 43. Greco FA, Coletti A, Camaioni E, Carotti A, Marinozzi M, Gioiello A, et al. The 822 Janus-faced nature of IDO1 in infectious diseases: challenges and therapeutic 823 opportunities. Future Med Chem. 2016;8: 39-54. doi:10.4155/fmc.15.165

824 44. Melé M, Ferreira PG, Reverter F, DeLuca DS, Monlong J, Sammeth M, et al.

825 The human transcriptome across tissues and individuals. Science. 2015;348: 660826 665. doi:10.1126/science.aaa0355 
827 45. Yamazaki F, Kuroiwa T, Takikawa O, Kido R. Human indolylamine 2,3-

828 dioxygenase. Its tissue distribution, and characterization of the placental enzyme.

829 Biochem J. 1985;230: 635-638. doi:10.1042/bj2300635

830 46. Hughes TK, Wadsworth MH, Gierahn TM, Do T, Weiss D, Andrade PR, et al.

831 Second-Strand Synthesis-Based Massively Parallel scRNA-Seq Reveals Cellular

832 States and Molecular Features of Human Inflammatory Skin Pathologies. Immunity.

833 2020;53: 878-894.e7. doi:10.1016/j.immuni.2020.09.015

834 47. Gautam US, Foreman TW, Bucsan AN, Veatch AV, Alvarez X, Adekambi T, et

835 al. In vivo inhibition of tryptophan catabolism reorganizes the tuberculoma and

836 augments immune-mediated control of Mycobacterium tuberculosis. Proc Natl Acad

837 Sci U S A. 2018;115: E62-E71. doi:10.1073/pnas.1711373114

838 48. Yeung AWS, Terentis AC, King NJC, Thomas SR. Role of indoleamine 2,3-

839 dioxygenase in health and disease. Clin Sci. 2015;129: 601-672.

840 doi:10.1042/CS20140392

841 49. Denys A, Allain F. The emerging roles of heparan sulfate 3-O-

842 sulfotransferases in cancer. Front Oncol. 2019;9. doi:10.3389/fonc.2019.00507

843 50. Yamauchi PS, Bleharski JR, Uyemura K, Kim J, Sieling PA, Miller A, et al. A

844 Role for CD40-CD40 Ligand Interactions in the Generation of Type 1 Cytokine

845 Responses in Human Leprosy. J Immunol. 2000;165: 1506-1512.

846 doi:10.4049/jimmunol.165.3.1506

847 51. Heim A. Highly sensitive detection of gene expression of an intronless gene:

848 amplification of mRNA, but not genomic DNA by nucleic acid sequence based 
849 amplification (NASBA). Nucleic Acids Res. 1998;26: 2250-2251.

850 doi:10.1093/nar/26.9.2250

52. Patterson SS, Casper ET, Garcia-Rubio L, Smith MC, Paul JH. Increased

852 precision of microbial RNA quantification using NASBA with an internal control. J

853 Microbiol Methods. 2005;60: 343-352. doi:10.1016/j.mimet.2004.10.011

854 53. Ganguli A, Ornob A, Spegazzini N, Liu Y, Damhorst G, Ghonge T, et al.

855 Pixelated spatial gene expression analysis from tissue. Nat Commun. 2018;9.

856 doi:10.1038/s41467-017-02623-9

857 54. Pandey M, Singh D, Onteru SK. Reverse transcription loop-mediated

858 isothermal amplification (RT-LAMP), a light for mammalian transcript analysis in low-

859 input laboratories. J Cell Biochem. 2018;119: 4334-4338. doi:10.1002/jcb.26624

860 55. Broughton JP, Deng X, Yu G, Fasching CL, Servellita V, Singh J, et al.

861 CRISPR-Cas12-based detection of SARS-CoV-2. Nat Biotechnol. 2020;38: 870-

862 874. doi:10.1038/s41587-020-0513-4

863 56. Barbieri RR, Manta FSN, Moreira SJM, Sales AM, Nery JAC, Nascimento

864 LPR, et al. Quantitative polymerase chain reaction in paucibacillary leprosy

865 diagnosis: A follow-up study. PLoS Negl Trop Dis. 2019;13: e0007147.

866 doi:10.1371/journal.pntd.0007147

867 57. Strassner JP, Rashighi M, Ahmed Refat M, Richmond JM, Harris JE. Suction

868 blistering the lesional skin of vitiligo patients reveals useful biomarkers of disease

869 activity. J Am Acad Dermatol. 2017;76: 847-855.e5. doi:10.1016/j.jaad.2016.12.021

870 58. Elamin AA, Stehr M, Singh M. Lipid Droplets and Mycobacterium leprae

871 Infection. J Pathog. 2012;10. doi:10.1155/2012/361374 
872 59. Lobato LS, Rosa PS, Ferreira J da S, Neumann A da S, da Silva MG, do

873 Nascimento DC, et al. Statins increase rifampin mycobactericidal effect. Antimicrob

874 Agents Chemother. 2014;58: 5766-74. doi:10.1128/AAC.01826-13

875 60. Wang D, Zhang D-F, Li G-D, Bi R, Fan Y, Wu Y, et al. A pleiotropic effect of 876 the APOE gene: association of APOE polymorphisms with multibacillary leprosy in

877 Han Chinese from Southwest China. Br J Dermatol. 2018;178: 931-939.

878 doi:10.1111/bjd.16020

879 61. Fabel A, Giovanna Brunasso AM, Schettini AP, Cota C, Puntoni M, Nunzi E, 880 et al. Pathogenesis of Leprosy. Am J Dermatopathol. 2019;41: 422-427.

881 doi:10.1097/DAD.0000000000001310

882 62. Iyer AM, Mohanty KK, van Egmond D, Katoch K, Faber WR, Das PK, et al. 883 Leprosy-specific B-cells within cellular infiltrates in active leprosy lesions. Hum 884 Pathol. 2007;38: 1065-1073. doi:10.1016/j.humpath.2006.12.017

885 63. Medeiros RCA, Girardi K do C de V, Cardoso FKL, Mietto B de S, Pinto TG 886 de T, Gomez LS, et al. Subversion of Schwann Cell Glucose Metabolism by

887 Mycobacterium leprae. J Biol Chem. 2016;291: 21375-21387.

888 doi:10.1074/jbc.M116.725283

889 64. de Toledo-Pinto TG, Ferreira ABR, Ribeiro-Alves M, Rodrigues LS, Batista890 Silva LR, Silva BJ de A, et al. STING-Dependent 2'-5' Oligoadenylate Synthetase891 Like Production Is Required for Intracellular Mycobacterium leprae Survival. J Infect 892 Dis. 2016;214: 311-320. doi:10.1093/infdis/jiw144 
893 65. Hess S, Rambukkana A. Bacterial-induced cell reprogramming to stem cell-

894 like cells: new premise in host-pathogen interactions. Curr Opin Microbiol. 2015;23:

895 179-188. doi:10.1016/j.mib.2014.11.021

896 66. Vandewalle C, Comijn J, De Craene B, Vermassen P, Bruyneel E, Andersen

$897 \mathrm{H}$, et al. SIP1/ZEB2 induces EMT by repressing genes of different epithelial cell-cell 898 junctions. Nucleic Acids Res. 2005;33: 6566-6578. doi:10.1093/nar/gki965

899 67. DaSilva-Arnold SC, Kuo CY, Davra V, Remache Y, Kim PCW, Fisher JP, et

900 al. ZEB2, a master regulator of the epithelial-mesenchymal transition, mediates

901 trophoblast differentiation. Mol Hum Reprod. 2018;25: 61-75.

902

doi:10.1093/molehr/gay053

903 68. Jiang Y, Zhou J, Hou D, Luo P, Gao H, Ma Y, et al. Prosaposin is a biomarker

904 of mesenchymal glioblastoma and regulates mesenchymal transition through the

905 TGF-ß1/Smad signaling pathway. J Pathol. 2019;249: 26-38. doi:10.1002/path.5278

906 69. Frugtniet BA, Martin TA, Zhang L, Jiang WG. Neural Wiskott-Aldrich

907 syndrome protein (nWASP) is implicated in human lung cancer invasion. BMC

908 Cancer. 2017;17. doi:10.1186/s12885-017-3219-3

909 70. Bendris N, Arsic N, Lemmers B, Blanchard JM. Cyclin A2, Rho GTPases and

910 EMT. Small GTPases. 2012;3: 225-228. doi:10.4161/sgtp.20791

911 71. Bhowmick NA, Ghiassi M, Bakin A, Aakre M, Lundquist CA, Engel ME, et al.

912 Transforming growth factor- $\beta 1$ mediates epithelial to mesenchymal

913 transdifferentiation through a RhoA-dependent mechanism. Mol Biol Cell. 2001;12:

914 27-36. doi:10.1091/mbc.12.1.27 
915 72. Salvi A, Thanabalu T. WIP promotes in-vitro invasion ability, anchorage

916 independent growth and EMT progression of A549 lung adenocarcinoma cells by

917 regulating RhoA levels. Biochem Biophys Res Commun. 2017;482: 1353-1359.

918 doi:10.1016/j.bbrc.2016.12.040

919 73. Wang Q, Yang X, Xu Y, Shen Z, Cheng H, Cheng F, et al. RhoA/Rho-kinase

920 triggers epithelial-mesenchymal transition in mesothelial cells and contributes to the

921 pathogenesis of dialysis-related peritoneal fibrosis. Oncotarget. 2018;9: 14397-

922 14412. doi:10.18632/oncotarget.24208

923 74. Wang J, Chen L, Li Y, Guan XY. Overexpression of cathepsin Z contributes to

924 tumor metastasis by inducing epithelial-mesenchymal transition in hepatocellular

925 carcinoma. PLoS ONE. 2011;6. doi:10.1371/journal.pone.0024967

926 75. Lin CY, Tsai PH, Kandaswami CC, Lee PP, Huang CJ, Hwang JJ, et al.

927 Matrix metalloproteinase-9 cooperates with transcription factor Snail to induce

928 epithelial-mesenchymal transition. Cancer Sci. 2011;102: 815-827.

929 doi:10.1111/j.1349-7006.2011.01861.x

930 76. Peinado H, del Carmen Iglesias-de la Cruz M, Olmeda D, Csiszar K, Fong

931 KSK, Vega S, et al. A molecular role for lysyl oxidase-like 2 enzyme in Snail

932 regulation and tumor progression. EMBO J. 2005;24: 3446-3458.

933 doi:10.1038/sj.emboj.7600781

934 77. Tam SY, Wu VWC, Law HKW. Hypoxia-Induced Epithelial-Mesenchymal

935 Transition in Cancers: HIF-1a and Beyond. Front Oncol. 2020;10.

936 doi:10.3389/fonc.2020.00486 
937 78. Zhu Y, Tan J, Xie H, Wang J, Meng X, Wang R. HIF-1 a regulates EMT via the

938 Snail and $\beta$-catenin pathways in paraquat poisoning-induced early pulmonary

939 fibrosis. J Cell Mol Med. 2016;20: 688-697. doi:10.1111/jcmm.12769

940 79. Lyrio ECD, Campos-Souza IC, Corrêa LCD, Lechuga GC, Verícimo M, Castro

$941 \mathrm{HC}$, et al. Interaction of Mycobacterium leprae with the HaCaT human keratinocyte

942 cell line: new frontiers in the cellular immunology of leprosy. Exp Dermatol. 2015;24:

943 536-542. doi:10.1111/exd.12714

944 80. Okada S, Komura J, Nishiura M. Mycobacterium leprae found in epidermal

945 cells by electron microscopy. IntJLeprOther MycobactDis. 1978;46: 30-34.

946 81. Pivarcsi A, Kemény L, Dobozy A. Innate Immune Functions of the

947 Keratinocytes. Acta Microbiol Immunol Hung. 2004;51: 303-310.

948 doi:10.1556/AMicr.51.2004.3.8

949 82. Pivarcsi A, Nagy I, Lajos K. Innate Immunity in the Skin: How Keratinocytes

950 Fight Against Pathogens. Curr Immunol Rev. 2005;1: 29-43.

951 doi:10.2174/1573395052952941

952 83. Damsky W, Thakral D, McGeary MK, Leventhal J, Galan A, King B. Janus 953 kinase inhibition induces disease remission in cutaneous sarcoidosis and granuloma 954 annulare. J Am Acad Dermatol. 2020;82: 612-621. doi:10.1016/j.jaad.2019.05.098

955 84. Flynn JL, Chan J, Lin PL. Macrophages and control of granulomatous 956 inflammation in tuberculosis. Mucosal Immunol. 2011;4: 271-278.

957 doi:10.1038/mi.2011.14

958 85. Locke LW, Crouser ED, White P, Julian MW, Caceres EG, Papp AC, et al. IL959 13-regulated Macrophage Polarization during Granuloma Formation in an In Vitro 
960 Human Sarcoidosis Model. Am J Respir Cell Mol Biol. 2019;60: 84-95. doi:10.1165/rcmb.2018-00530C

962 86. Manta FSN, Barbieri RR, Moreira SJM, Santos PTS, Nery JAC, Duppre NC, 963 et al. Quantitative PCR for leprosy diagnosis and monitoring in household contacts:

964 A follow-up study, 2011-2018. Sci Rep. 2019;9. doi:10.1038/s41598-019-52640-5

965 87. Brabaham Bioinformatics. FastQC: A Quality Control Tool for High

966 Throughput Sequence Data [Online]. 2015. Available:

967 http://www.bioinformatics.babraham.ac.uk/projects/fastqc/

968 88. Patro R, Duggal G, Love MI, Irizarry RA, Kingsford C. Salmon provides fast 969 and bias-aware quantification of transcript expression. Nat Methods. 2017;14: 417970 419. doi:10.1038/nmeth.4197

971 89. R Core Team. R: A language and environment for statistical computing.

972 Vienna, Austria; 2017. Available: https://www.r-project.org/

973 90. Soneson C, Love MI, Robinson MD. Differential analyses for RNA-seq:

974 transcript-level estimates improve gene-level inferences. F1000Research. 2016;4:

975 1521. doi:10.12688/f1000research.7563.2

976 91. Durinck S, Moreau Y, Kasprzyk A, Davis S, De Moor B, Brazma A, et al.

977 BioMart and Bioconductor: a powerful link between biological databases and

978 microarray data analysis. Bioinformatics. 2005;21: 3439-3440.

979 doi:10.1093/bioinformatics/bti525

980 92. Anders S, Huber W. Differential expression analysis for sequence count data.

981 Genome Biol. 2010;11: R106. doi:10.1186/gb-2010-11-10-r106 
982 93. Love MI, Huber W, Anders S. Moderated estimation of fold change and

983 dispersion for RNA-seq data with DESeq2. Genome Biol. 2014;15: 550.

984 doi:10.1186/s13059-014-0550-8

985 94. Zhu A, Ibrahim JG, Love MI. Heavy-Tailed prior distributions for sequence 986 count data: Removing the noise and preserving large differences. Bioinformatics. 2019;35: 2084-2092. doi:10.1093/bioinformatics/bty895

95. Gagnon-Bartsch JA, Speed TP. Using control genes to correct for unwanted 989 variation in microarray data. Biostatistics. 2012;13: 539-552.

990 doi:10.1093/biostatistics/kxr034

991 96. Risso D, Ngai J, Speed TP, Dudoit S. Normalization of RNA-seq data using 992 factor analysis of control genes or samples. Nat Biotechnol. 2014;32: 896-902.

993 doi:10.1038/nbt.2931

994 97. Benjamini Y, Hochberg Y. Controlling the False Discovery Rate: A Practical 995 and Powerful Approach to Multiple Testing. Journal of the Royal Statistical Society. 996 Series B (Methodological). WileyRoyal Statistical Society; 1995.

997 doi:10.2307/2346101

998 98. Phipson B, Lee S, Majewski IJ, Alexander WS, Smyth GK. Robust 999 hyperparameter estimation protects against hypervariable genes and improves 1000 power to detect differential expression. Ann Appl Stat. 2016;10: 946-963. 1001 doi:10.1214/16-AOAS920

1002 99. Ritchie ME, Phipson B, Wu D, Hu Y, Law CW, Shi W, et al. limma powers 1003 differential expression analyses for RNA-sequencing and microarray studies. Nucleic 1004 Acids Res. 2015;43: e47. doi:10.1093/nar/gkv007 
1005 100. Smyth GK. Linear Models and Empirical Bayes Methods for Assessing

1006 Differential Expression in Microarray Experiments Linear Models and Empirical

1007 Bayes Methods for Assessing Differential Expression in Microarray Experiments.

1008 Stat Appl Genet Mol Biol. 2004;3: 1-26. doi:10.2202/1544-6115.1027

1009 101. Wickham H. ggplot2-Elegant Graphics for Data Analysis. 1st ed. New York,

1010 NY: Springer New York; 2009. doi:10.1007/978-0-387-98141-3

1011 102. Gu Z, Eils R, Schlesner M. Complex heatmaps reveal patterns and

1012 correlations in multidimensional genomic data. Bioinformatics. 2016;32: 2847-2849.

1013 doi:10.1093/bioinformatics/btw313

1014 103. Kolde R. pheatmap: Pretty Heatmaps. 2015. Available: https://cran.r-

1015 project.org/package=pheatmap

1016 104. Yu G, Wang L-G, Han Y, He Q-Y. clusterProfiler: an R Package for

1017 Comparing Biological Themes Among Gene Clusters. OMICS J Integr Biol. 2012;16:

1018 284-287. doi:10.1089/omi.2011.0118

1019 105. Carlson M. org.Hs.eg.db: Genome wide annotation for Human. 2019.

1020 Available: 10.18129/B9.bioc.org.Hs.eg.db

1021 106. Koressaar T, Remm M. Enhancements and modifications of primer design

1022 program Primer3. Bioinformatics. 2007;23: 1289-1291.

1023 doi:10.1093/bioinformatics/btm091

1024 107. Kõressaar T, Lepamets M, Kaplinski L, Raime K, Andreson R, Remm M.

1025 Primer3_masker: integrating masking of template sequence with primer design

1026 software. Bioinformatics. 2018;34: 1937-1938. doi:10.1093/bioinformatics/bty036 
1027 108. Untergasser A, Cutcutache I, Koressaar T, Ye J, Faircloth BC, Remm M, et al. 1028 Primer3—new capabilities and interfaces. Nucleic Acids Res. 2012;40: e115-e115. 1029 doi:10.1093/nar/gks596

1030 109. Ye J, Coulouris G, Zaretskaya I, Cutcutache I, Rozen S, Madden TL. Primer1031 BLAST: a tool to design target-specific primers for polymerase chain reaction. BMC 1032 Bioinformatics. 2012;13: 134. doi:10.1186/1471-2105-13-134

1033 110. Qu W, Shen Z, Zhao D, Yang Y, Zhang C. MFEprimer: Multiple factor 1034 evaluation of the specificity of PCR primers. Bioinformatics. 2009;25: 276-278. 1035 doi:10.1093/bioinformatics/btn614

1036 111. Wang K, Li H, Xu Y, Shao Q, Yi J, Wang R, et al. MFEprimer-3.0: Quality 1037 control for PCR primers. Nucleic Acids Res. 2019;47: W610-W613.

1038 doi:10.1093/nar/gkz351

1039 112. Ramakers C, Ruijter JM, Lekanne Deprez RH, Moorman AFM. Assumption1040 free analysis of quantitative real-time polymerase chain reaction (PCR) data.

1041 Neurosci Lett. 2003;339: 62-66. doi:10.1016/S0304-3940(02)01423-4

1042 113. Ruijter JM, Ramakers C, Hoogaars WMH, Karlen Y, Bakker O, Van den hoff 1043 MJB, et al. Amplification efficiency: Linking baseline and bias in the analysis of 1044 quantitative PCR data. Nucleic Acids Res. 2009;37. doi:10.1093/nar/gkp045

1045 114. Vandesompele J, De Preter K, Pattyn ilip, Poppe B, Van Roy N, De Paepe A, 1046 et al. Accurate normalization of real-time quantitative RT-PCR data by geometric 1047 averaging of multiple internal control genes. Genome Biol. 2002;3: 34-1.

1048 doi:10.1186/gb-2002-3-7-research0034 
1049 115. Matz MV, Wright RM, Scott JG. No control genes required: Bayesian analysis

1050 of qRT-PCR data. PloS One. 2013;8: 1-12. doi:10.1371/journal.pone.0071448

1051 116. Steibel JP, Poletto R, Coussens PM, Rosa GJM. A powerful and flexible linear 1052 mixed model framework for the analysis of relative quantification RT-PCR data.

1053 Genomics. 2009;94: 146-152. doi:10.1016/j.ygeno.2009.04.008

1054 117. Fieller EC, Hartley HO, Pearson ES. TESTS FOR RANK CORRELATION

1055 COEFFICIENTS I. Biometrika. 1957;44: 470-481. doi:10.1093/biomet/44.3-4.470

1056 118. Makowski D, Ben-Shachar MS, Patil I, Lüdecke D. Methods and Algorithms

1057 for Correlation Analysis in R. J Open Source Softw. 2020;5: 2306.

1058 doi:10.21105/joss.02306

1059 119. Friedman J, Hastie T, Tibshirani R. Regularization paths for generalized linear 1060 models via coordinate descent. J Stat Softw. 2010;33: 1-22.

1061 doi:10.18637/jss.v033.i01

1062 120. Simon N, Friedman JH, Hastie T, Tibshirani R. Regularization Paths for Cox's 1063 Proportional Hazards Model via Coordinate Descent. J Stat Softw. 2011;39: 1-13. 1064 doi:10.18637/jss.v039.i05

1065 121. Tibshirani R. Regression Shrinkage and Selection via the Lasso. J R Stat Soc 1066 Ser B Methodol. 1996;58: 267-288.

1067 122. Hastie T, Tibshirani R, Wainwright M. Statistical Learning with Sparsity. 1st 1068 ed. Chapman and Hall/CRC; 2015.

1069 123. Davison AC, Hinley DV. Bootstrap Methods and Their Application. Cambrige 1070 University Press; 1997. Available: http://statwww.epfl.ch/davison/BMA/ 
1071 124. DeLong ER, DeLong DM, Clarke-Pearson DL. Comparing the Areas under

1072 Two or More Correlated Receiver Operating Characteristic Curves: A Nonparametric

1073 Approach. Biometrics. 1988;44: 837. doi:10.2307/2531595

1074 125. Robin X, Turck N, Hainard A, Tiberti N, Lisacek F, Sanchez JC, et al. pROC:

1075 An open-source package for $\mathrm{R}$ and $\mathrm{S}+$ to analyze and compare ROC curves. BMC

1076 Bioinformatics. 2011;12: 77. doi:10.1186/1471-2105-12-77

1077 126. Sun X, Xu W. Fast implementation of DeLong's algorithm for comparing the 1078 areas under correlated receiver operating characteristic curves. IEEE Signal Process

1079 Lett. 2014;21: 1389-1393. doi:10.1109/LSP.2014.2337313

\section{Supporting Information}

1081 S1 Appendix. Linking expression profiles to mycobacteria species.

1082 S1 Fig. Gene expression in MB and PB groups from test and training datasets.

1083 Normalized $\log _{2}$ expression values per group from (A) this study RNA-seq dataset or

(B) Belone et al. (GSE74481) [24]. The genes shown were selected in $25 \%-50 \%$ of the LASSO models (Fig 4B) according to the bootstrap. MB, multibacillary leprosy; PB, paucibacillary leprosy; TT, tuberculoid leprosy; BT, borderline-tuberculoid; BB,

1087 borderline-borderline; BL, borderline-lepromatous; LL, lepromatous. Each point 1088 represents an independent skin biopsy from a patient. Y-axis values are not comparable between panels $\mathrm{A}$ and $\mathrm{B}$.

S2 Fig. Strongest correlations between the average expression of genes associated with keratinocyte/cornification against dedifferentiation-related genes using Montoya et al. RNA-seq dataset [28]. Scatter plots of scores (average 
1093 normalized $\log _{2}$ expression) calculated from genes with previously documented down-

1094 regulation in leprosy skin lesions against dedifferentiation-related genes with Montoya

1095 et al. RNA-seq dataset (GSE125943) [28]. Lines were drawn based on intercept and

1096 beta estimates from robust linear regression for all samples (black) or separately for

1097 TL (tuberculoid leprosy, blue), and LL (lepromatous leprosy, red). X-axis shows $\log _{2}$

1098 normalized expression values. Spearman's rho are shown along with nominal 95\%

1099 confidence intervals inside the plots. Most genes shown have FDR $<0.1$ and rho $\leq-$

$1100 \quad$ 0.6. Related to figure 6.

1101 S3 Fig. Strongest correlations between modulated genes from

1102 keratinocyte/cornification and dedifferentiation-related genes using Belone et

1103 al. microarray dataset (GSE74481) [24]. Heat plot with Spearman's rho correlation

1104 coefficient of the strongest correlations from all ontologies screened after multiple

1105 testing adjustment (BH-FDR). Most genes shown have FDR $\leq 0.0001$ and rho $\leq-0.7$.

1106 Bottom colored rectangles indicate which category the gene was present (some genes

1107 co-occur). Related to figure 6.

1108 S1 Table. Demographic and clinical metadata from human participants.

1109 S2 Table. Genes differentially expressed from leprosy vs. non-leprosy with

$1110\left|\log _{2} \mathrm{FC}\right| \geq 1$ and FDR $\leq \mathbf{0 . 0 1}$

1111 S3 Table. Over-representation analysis (ORA) for leprosy vs. non-leprosy (up-

1112 regulated) differentially expressed genes.

1113 S4 Table. ROC analysis from RNA-seq dataset using leprosy vs. non-leprosy

1114 samples. 
1115 S5 Table. Posterior $\log _{2}$ FC estimates, 95\% credible intervals and MCMC P.

1116 values from PB-OD and MB-OD comparisons.

1117 S6 Table. ROC analysis results using RT-qPCR with the validation dataset 1118 (Related to Fig 3). 95\% confidence intervals are shown, except for AUCs of 1.0. The 1119 table is sorted from highest to lowest AUC.

1120 S7 Table. $\log _{2} \mathrm{FC}$ estimates, confidence intervals, and Dunnet $\boldsymbol{P}$-values from 1121 distinct mycobacterial stimuli in human macrophages in vitro.

1122 S8 Table. Genes differentially expressed from multibacillary paucibacillary 1123 leprosy with $\left|\log _{2} \mathrm{FC}\right| \geq 1$ and FDR $\leq 0.01$.

1124 S9 Table. Over-representation analysis (ORA) for MB vs. PB (up-regulated) 1125 differentially expressed genes.

1126 S10 Table. Over-representation analysis (ORA) for MB vs. PB (down-regulated) 1127 differentially expressed genes.

1128 S11 Table. Oligonucleotide sequences. 